\title{
Caspase-10: a molecular switch from cell-autonomous apoptosis to communal cell death in response to chemotherapeutic drug treatment
}

\begin{abstract}
Andrea Mohr ${ }^{1}$, Laura Deedigan ${ }^{2}$, Sylwia Jencz ${ }^{1}$, Yasamin Mehrabadi ${ }^{1}$, Lily Houlden ${ }^{1,3}$, Stella-Maris Albarenque ${ }^{2}$ and Ralf M Zwacka ${ }^{*, 1}$
The mechanisms of how chemotherapeutic drugs lead to cell cycle checkpoint regulation and DNA damage repair are well understood, but how such signals are transmitted to the cellular apoptosis machinery is less clear. We identified a novel apoptosisinducing complex, we termed FADDosome, which is driven by ATR-dependent caspase-10 upregulation. During FADDosomeinduced apoptosis, CFLIP is ubiquitinated by TRAF2, leading to its degradation and subsequent FADD-dependent caspase-8 activation. Cancer cells lacking caspase-10, TRAF2 or ATR switch from this cell-autonomous suicide to a more effective, autocrine/ paracrine mode of apoptosis initiated by a different complex, the FLIPosome. It leads to processing of cFLIPL to cFLIP p43, TNF- $\alpha$ production and consequently, contrary to the FADDosome, p53-independent apoptosis. Thus, targeting the molecular levers that switch between these mechanisms can increase efficacy of treatment and overcome resistance in cancer cells.
\end{abstract}

Cell Death and Differentiation (2018) 25, 340-352; doi:10.1038/cdd.2017.164; published online 3 November 2017

Anti-tumour drugs exert their effect by inducing programmed cell death. ${ }^{1}$ Apoptosis can be initiated by various stimuli and factors including growth factor withdrawal, UV, $\gamma$-irradiation, signalling by death receptors or chemotherapeutic drugs ${ }^{2}$ and has been broadly separated into two distinct processes: (a) signal-mediated apoptosis, also known as extrinsic cell death triggered by binding of death ligands such as FasL/CD95L or TRAIL to their cognate receptors ${ }^{3}$ and (b) cell death caused by intracellular stress, as for instance, initiated by cytotoxic drugs, also known as the intrinsic pathway that typically uses caspase- 9 as the initiator caspase. ${ }^{4-6}$ However, there is also ample evidence for the existence and function of other initiator caspase activities upstream of mitochondria in stress- and drug-induced cell death. ${ }^{7-10}$

Recently, apoptosis-induction mechanisms involving caspase-8 have been discovered in connection with compounds that block inhibitor-of-apoptosis-proteins (IAPs). Treatment with such compounds resulted in proteasomal degradation of clAP1, clAP2 and XIAP leading to NF- $k \mathrm{~B}$ activation, upregulation of TNF- $a$ production and subsequent autocrine TNFR1- and caspase-8-mediated apoptosis. ${ }^{11-15}$ Later, the topoisomerase II inhibitor etoposide, which gives rise to DNA double strand breaks, was shown to cause apoptosis through a seemingly similar mechanism in HeLa cells. ${ }^{16}$ In addition, it was shown that IAP inhibition either alone or in combination with etoposide gives rise to an apoptosisinducing, RIP1-dependent complex termed RIPoptosome. ${ }^{14,15}$ However, etoposide was previously reported to engage the classic caspase-9-mediated pathway. ${ }^{17,18}$ In view of these controversial data, it appears that aside from the canonical caspase- 9 pathway several other, possibly cell type-specific, cytotoxic drug-triggered apoptosis-induction mechanisms exist. Furthermore, it remains elusive how the cellular damage caused by these drugs is sensed, and then signalled up to the varying apoptosis pathways and mechanisms. The two serine/threonine protein kinases ATR and ATM are key factors involved in the DNA damage response, but there are only a few reports describing how they function in apoptosis signalling. ${ }^{19}$ ATM has been linked to cytokine and caspase signalling upon strong genotoxic damage as well as to PIDD phosphorylation required for RAIDD binding and caspase- 2 activation. ${ }^{16,20}$ However, very little is known how these responses vary based on treatment type and molecular make-up of cancer cells.

Given the growing complexity of how different cancer treatments trigger various cell death mechanisms, it is important to unravel the cellular and molecular contexts that determine the utilisation of the various pathways in cancer cells, and to exploit this new knowledge for diagnostic and therapeutic purposes.

\section{Results}

5FU-induced apoptosis is mediated by a caspase-9- and RIPoptosome-independent process that is initiated by caspase-8. In order to reduce the complexity caused by overlapping cell death modi we applied a prescreen to identify compounds that act solely through apoptosis mechanisms that have not been previously described with the aim of identifying novel pathways (Figure 1a). Through this experimental strategy, we found that $5 \mathrm{FU}$ induces apoptosis via a potentially novel mechanism (Supplementary Figures 1a-e). AnnexinV/PI staining, DNA hypodiploidy assays, caspase western blots and

${ }^{1}$ School of Biological Sciences, Cancer and Stem Cell Biology Group, University of Essex, Colchester CO4 3SQ, UK; ${ }^{2}$ National Centre for Biomedical Engineering Science, National University of Ireland Galway, Galway, Ireland and ${ }^{3}$ School of Biosciences and Medicine, University of Surrey, Guildford GU2 7XH, UK

${ }^{*}$ Corresponding author: RM Zwacka, School of Biological Sciences, Cancer and Stem Cell Biology Group, University of Essex, Colchester Essex CO4 3SQ, UK. E-mail: rzwacka@essex.ac.uk

Received 06.2.17; revised 15.8.17; accepted 17.8.17; Edited by D Vaux; published online 03.11.17 


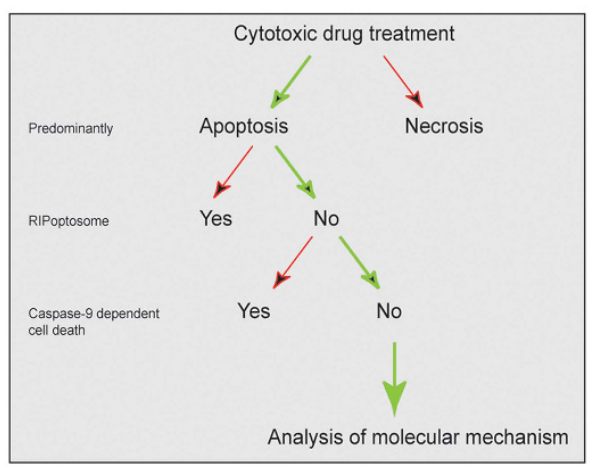

c
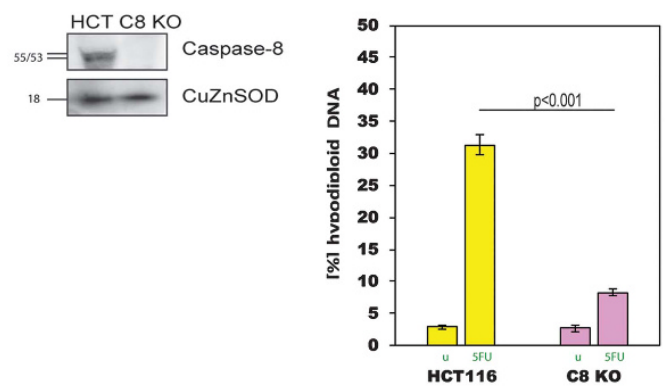
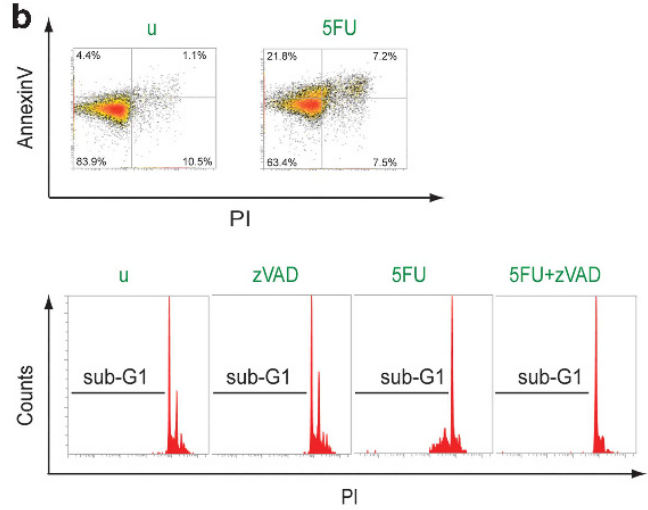

d

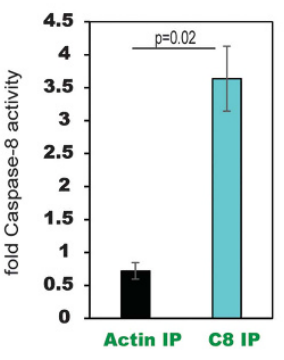

e

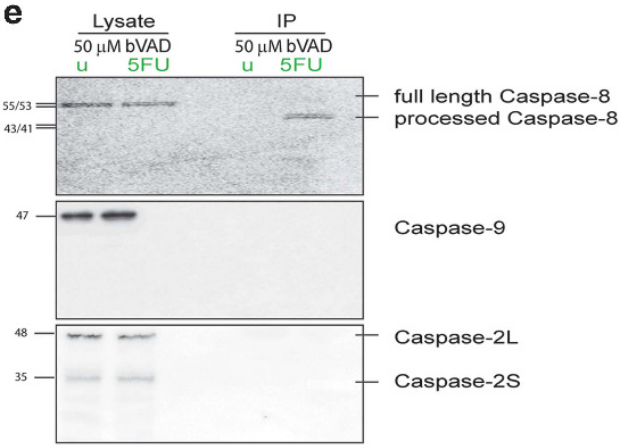

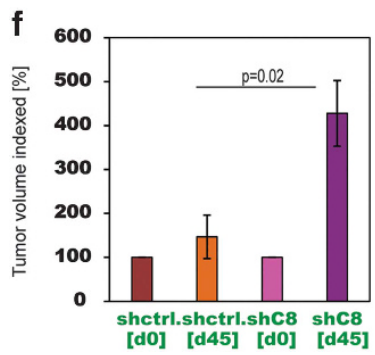

Figure 1 5FU-induced apoptosis is initiated by caspase-8. (a) Experimental strategy to identify compounds that act solely through potentially novel apoptosis mechanisms. (b) (Top) AnnexinV/PI staining of HCT116 cells treated with 5FU. (Lower) Caspase-dependent apoptosis induction was assessed using zVAD in connection with DNA hypodiploidy assay. Representative results are shown. (c) (Left) Western blot against caspase-8 with lysates from HCT116 and C8 KO cells. (Right) Apoptosis was measured in response to $5 \mathrm{FU}$ in these cells. Data are plotted as mean \pm S.E.M. $(n=3)$. (d) Caspase-8 activity was measured after $5 \mathrm{FU}$ treatment in HCT116 cells. Activity is expressed as fold-caspase-8 activation. Immunoprecipitations (IP) with a control antibody (Actin IP) served as specificity control. Data are plotted as mean \pm S.E.M. ( $n \geq 3$ ). (e) Western blots of agarose-streptavidin precipitates from 5FU/bVAD-treated cells were probed with caspase-8, -9 and -2 antibodies. (f) Xenografts from HCT.shC8 and HCT.shctrl cells were treated with 5FU. End point tumour volumes are depicted in relation to starting volumes (set to 100) (animal numbers/group: $n=6 /$ shctrl, $n=3 /$ shC8)

measurements of mitochondrial membrane potential of cells treated with 5FU alone or in combination with ZVAD confirmed that $5 \mathrm{FU}$ induces apoptosis and other apoptotic processes in a caspase-dependent manner (Figure $1 \mathrm{~b}$ and Supplementary Figures 2a-d). To test the causal involvement of different initiator caspases, we knocked-out caspase-8 by CRISPR/ Cas9 gene editing and found that these cells were resistant to 5FU-induced apoptosis (Figure 1c). Silencing of caspase-8 by RNAi confirmed these findings, whereas targeting of caspase2 and caspase- 9 had no significant impact on cell death levels (Supplementary Figures 2e-k). In contrast, etoposide-induced cell death was not affected by silencing or knockout of caspase-8 (Supplementary Figures $2 \mathrm{e}$ and $2 \mathrm{l}$ ). Silencing of
cFLIP did not significantly impact on 5FU-induced apoptosis in HCT116 cells (Supplementary Figure $2 \mathrm{~m}$ ). In addition, whereas 5FU showed caspase-8 activity in a luciferasebased assay, etoposide did not (Figure $1 \mathrm{~d}$ and Supplementary Figure 2n). To validate and verify caspase- 8 as the proximal caspase in 5FU-induced apoptosis, we carried out a molecular trapping assay using a biotinylated caspase inhibitor (bVAD). For 5FU-treated HCT116 cells this assay revealed caspase-8 as the initiator caspase, whereas caspase- 9 and caspase-2 could not be detected (Figure 1e). Although not all drugs acted via this pathway, for example, etoposide, others also required the presence of caspase-8 such as Raltitrexed or the topoisomerase I inhibitor Irinotecan (Supplementary 
a

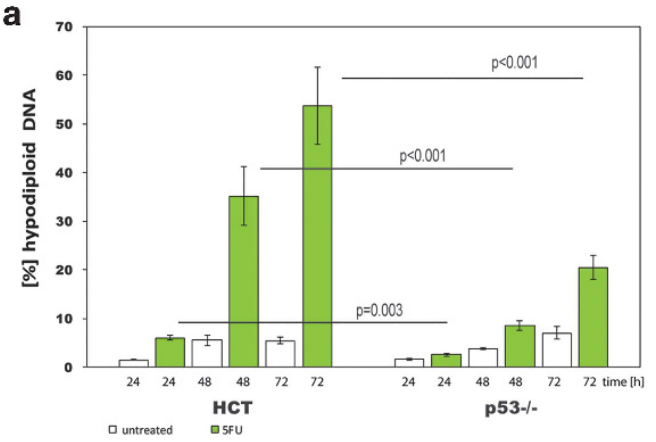

d

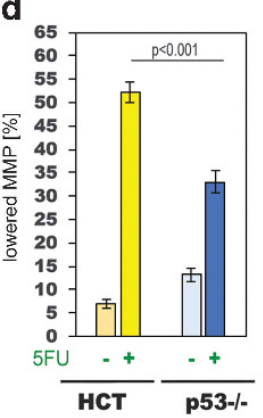

e

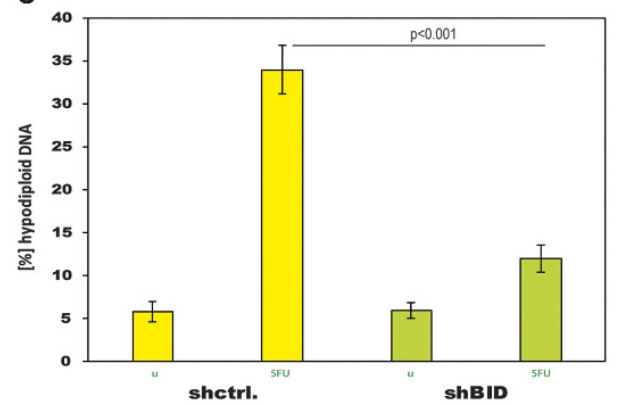

b

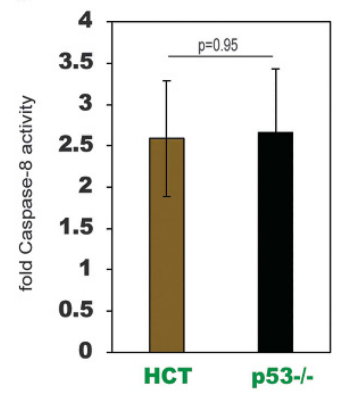

C

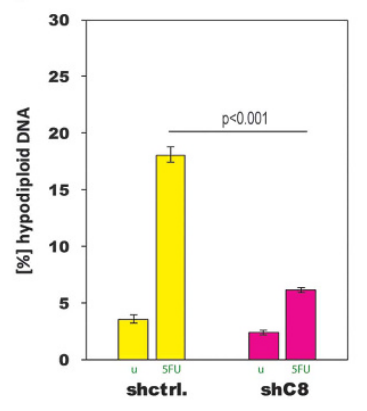

g

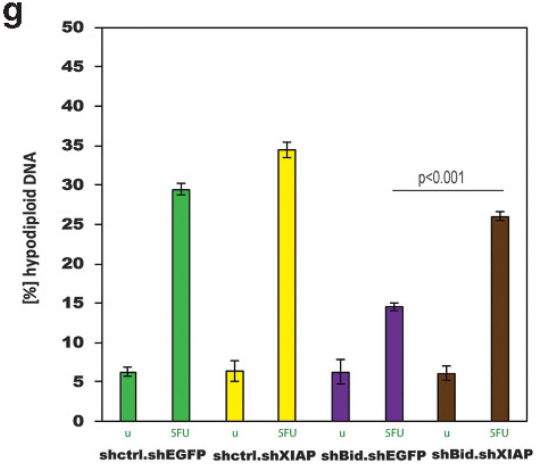

h

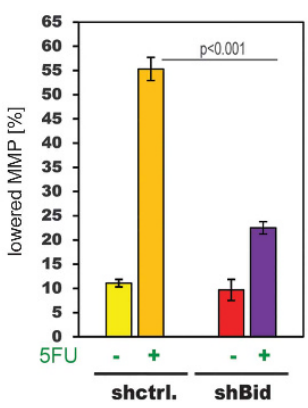

f

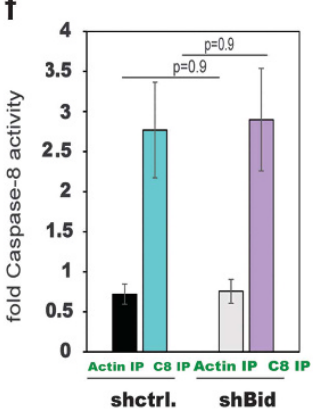

Figure 2 Caspase-8 activation is p53- and death receptor-independent. (a) HCT116 and HCTp53- / - (p53-/ - ) cells were treated with $5 \mathrm{FU}$ for 24,48 and $72 \mathrm{~h}$ before apoptosis was measured. Data are plotted as mean \pm S.E.M. $(n \geq 3)$. (b) Caspase-8 activity following 5FU treatment was measured in HCT116 and p53-/ - cells. Data are plotted as mean \pm S.E.M. $(n=4)$. (c) Caspase-8 was silenced in p53-/ - cells (shC8) and apoptosis measured $72 \mathrm{~h}$ post-treatment. Control knockdown cells (shctrl.) were used for comparison. Data are plotted as mean \pm S.E.M. $(n=3)$. (d) MMP measurements in HCT116 and p53- - cells before $(-)$ and after $(+) 5 F U$ treatment. Data are plotted as mean \pm S.E.M. $(n=3)$. (e) Apoptosis and changes in MMP after 5FU treatment were measured in stable Bid-silenced HCT116 cells (shBid). Data are plotted as mean \pm S.E.M. $(n=3)$. (f) Caspase-8 activity following 5FU treatment was measured in HCT.shBid cells. Data are plotted as mean \pm S.E.M. $(n=4)$. (g) XIAP was silenced (Ad. shXIAP) in HCT.shctrl and HCT.shBid cells and apoptosis measured after $5 F U$ treatment. Data are plotted as mean \pm S.E.M. $(n=3)$. Controls were shEGFP (Ad.shEGFP) double knock-downs. (h) HCT116 cells were silenced for p53 and XIAP (Ad.shp53 and Ad.shXIAP) and apoptosis measured following 5FU treatment. Ad.shEGFP and Ad.shsc served as double knockdown control. Data are plotted as mean \pm S.E.M. $(n \geq 3)$.

Figure 20). To test the impact of caspase-8 on clonogenicity and relevance in $5 \mathrm{FU}$ responses in vivo, we carried out colony forming assays (CFAs) and established xenografts. The CFAs revealed that silencing of caspase-8 allowed substantial survival and outgrowth, in contrast to controls (Supplementary Figure $2 p$ ). Similar results were obtained in the xenograft study (Figure $1 f$ and Supplementary Figure 2q).

Caspase-8 activation is p53- and death receptorindependent. Next, we analysed whether 5FU-induced caspase-8 activation was p53 dependent. ${ }^{21}$ We compared p53-proficient HCT116 and HCTp53 - / - cells for caspase-8 activity following 5FU treatment. Despite lower apoptosis levels in the p53-null cells (Figure 2a), caspase-8 activation was unchanged in these cells as compared with their isogenic parental cells (Figure 2b). The importance of caspase- 8 even in the p53-null context was underscored by the fact that apoptosis, albeit at overall low levels, was significantly reduced by silencing of caspase-8 (Figure 2c). As mitochondrial depolarisation in response to 5FU was lower in HCTp53-/ - than in HCT116 cells (Figure 2d) it appears that the signal from activated caspase- 8 onto mitochondria was attenuated in the p53-negative cells, resulting in diminished caspase-3 activation. Activated 
caspase-8 signals to mitochondria via the $\mathrm{BH} 3-$ only protein Bid. When we silenced Bid in HCT116 cells (HCT.shBid), we found significantly decreased apoptosis and mitochondrial depolarisation after treatment with $5 \mathrm{FU}$, but no reduction in caspase- 8 activity (Figures $2 e$ and $f$ and Supplementary Figure 3a). Thus, Bid is an essential signalling intermediate in 5FU-induced apoptosis, necessary for mitochondrial activation. As we demonstrated that caspase- 9 is not required, we hypothesised that not cytochrome c, but other factors, Smac/ DIABLO in particular, are important to overcome XIAPenforced inhibition of executioner caspase activation. We therefore, silenced XIAP in HCT.shBid cells, mimicking the release of Smac/DIABLO, and treated with 5FU. Such cells showed restored apoptosis and caspase-3 activation to almost parental HCT116 levels (Figure $2 \mathrm{~g}$ and Supplementary Figure 3b). Similarly, when we knocked down XIAP in p53-silenced cells we observed the same increase in apoptosis (Figure 2h). Thus, p53 is involved in the execution of 5FU-induced apoptosis via engagement of mitochondria, but not needed for the initiation of cell death at the level of caspase-8 activation.

Caspase-10 is upregulated in response to $5 \mathrm{FU}$ in a p53independent manner and forms a complex with FADD and caspase-8. In order to elucidate the underlying mechanism of caspase-8 activation in response to 5FU, we carried out an RNA-Seq analysis. From 568 genes that were significantly upregulated (Supplementary Table 1), five were potential caspase-8-binding partners and also upregulated as proteins (Figures $3 a$ and $b$ and Supplementary Table 2). Of these, CD95, TRAIL-R1 (TNFRSF10A) and TRAIL-R2 (TNFRSF10B) are p53-target genes and were therefore not good candidates as drivers for 5FU-induced, p53independent caspase-8 activation. Furthermore, blocking these receptors with neutralising antibodies caused no change in apoptosis levels (Supplementary Figure 4a). As caspase-10 and clAP2 upregulations were p53-independent (Figure 3c), we tested their capacity to induce apoptosis in HCT116 cells as compared with HCT.shC8 cells. Forced expression of caspase-10 but not clAP2 gave rise to caspase-8-driven apoptosis implicating caspase-10 in the formation of the caspase- 8 activation complex (Figure $3 \mathrm{~d}$ and Supplementary Figure 4b). Indeed, when we immunoprecipitated caspase-8 from 5FU-treated HCT116 cells we could detect coprecipitation of processed caspase-10 and the adaptor protein FADD, but not clAP2 or the death receptors (Figure $3 e$ and Supplementary Figure 4c). These results were confirmed in caspase-10-overexpressing cells, that is, after immunoprecipitation with caspase-8 antibodies, we were able to detect caspase-10 and FADD (Figure 3f). Furthermore, when we pulled-down overexpressed tagged versions of FADD in 5FU-treated 293 cells we were able to co-precipitate caspase-8 and caspase-10, and could also demonstrate FADD multimerisation in these cells (Supplementary Figure 4d). Thus, an induced complex containing FADD, caspase-10, and caspase-8 appeared to be responsible for the activation of caspase-8 and apoptosis induction. The formation of such a complex was corroborated by a sucrose gradient analysis that showed a shift of caspase-8, FADD and caspase-10 to higher molecular weight fractions ( 2 MDa) after 5FU treatment (Supplementary Figure $4 \mathrm{e}$ ). This shift of FADD and caspase-10 was absent in HCT.shC8 cells, but not in HCT.shBid cells, demonstrating the specificity of the analysis (Supplementary Figure 4f). To further elucidate the role of FADD and caspase-10, we generated respective knockdown cell lines (Supplementary Figure $4 \mathrm{~g}$ ). Silencing of FADD in HCT116 and HT-29 cells resulted in inhibition of both 5FU-induced apoptosis and caspase-8 activation (Figures $3 \mathrm{~g}$ and h), as well as a lack of a shift of caspase-8 and caspase10 in sucrose gradient analyses (Supplementary Figure 4h). On the other side knocking down of caspase-10 surprisingly led to significantly increased levels of cell death, which could still be blocked by the caspase inhibitor zVAD (Figure $3 \mathrm{i}$ and Supplementary Figure 4i). Thus, apoptosis in HCT.shC10 cells is a caspase-dependent process similar to HCT116 cells, but the markedly higher levels pointed to a potentially different and distinct mechanism in these cells.

Lack of Caspase-10 leads to TNF-a production in response to $5 \mathrm{FU}$ and FADD-independent apoptosis. Studying HCT.shC10 cells in more detail revealed, that similar to HCT116 cells, 5FU led to caspase-8 activation and caspase-8-dependent cell death, but silencing of FADD in HCT.shC10 cells did not result in apoptosis resistance (Figure 4a). The FADD-independency was confirmed by a lack of FADD multimerisation in HCT.shC10 cells in response to 5FU and a lack of a shift of FADD in sucrose gradient analyses (Supplementary Figure 5a). These results indicate that caspase-10 deficiency indeed leads to a switch to a different apoptosis mechanism. Next, we examined whether death receptors/death ligands were behind 5FU-induced caspase-8 activation and apoptosis in caspase-10 knockdown cells. Although both FasL and TRAIL-blocking antibodies did not affect cell death levels, antibodies directed against TNF- $a$ and its receptor TNFR1 significantly decreased apoptosis (Figure $4 \mathrm{~b}$ and Supplementary Figure 5b). As this was not the case in HCT116 cells (Supplementary Figure 5b), we concluded that in HCT.shC10 cells 5FU triggered the production of TNF- $a$, which in turn gave rise to apoptosis. An ELISA of supernatants from HCT. shC10 cells confirmed the TNF-a generation (Figure 4c). In addition, we discovered that $I_{\kappa} \mathrm{B}-a$ was phosphorylated and degraded in HCT.shC10, but not in control cells indicating that $5 \mathrm{FU}$-induced NF- $\mathrm{BB}$ activation gave rise to TNF- $a$ upregulation (Figure 4d). Blocking NF- $k$ B activation by overexpression of $I_{k} \mathrm{~B}-\mathrm{SR}$ in HCT.shC10 cells stopped the 5FU-induced TNF- $a$ production and inhibited apoptosis (Figure $4 \mathrm{e}$ and Supplementary Figure 5c). Cell death and TNF-a generation could also be blocked by silencing of caspase-8 in HCT.shC10 cells demonstrating that caspase-8 was not only required for the TNF- $a$-induced apoptosis, but was also crucial for the production of the cytokine in the first place (Figure 4f). Having excluded FADD as a functional partner in caspase-8 activation in HCT.shC10 cells, we turned to another known caspase-8-binding partner, cFLIP. We discovered that $C F L I P_{L}$ was degraded in HCT116 cells following 5FU treatment, but in HCT.shC10 cells the $\mathrm{CFLIP}$ levels hardly changed, and instead a cleaved form of $C F L I P_{L}$,

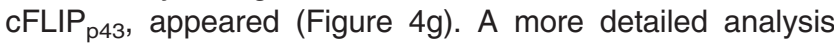
revealed that cleavage of $C F$ LIP ${ }_{L}$ to $\mathrm{CFLIP}_{\mathrm{p} 43}$ is required for 

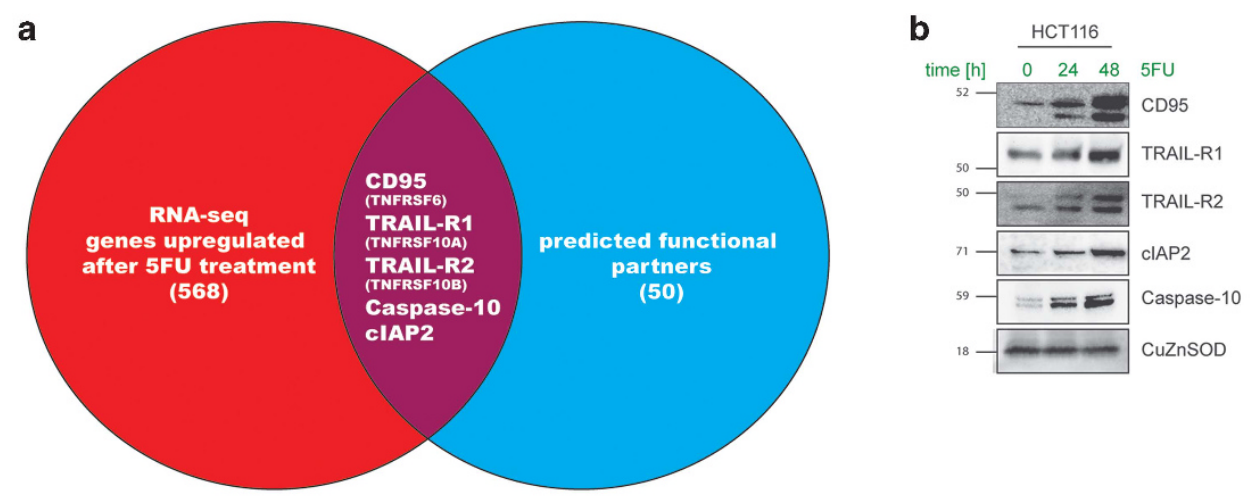

c
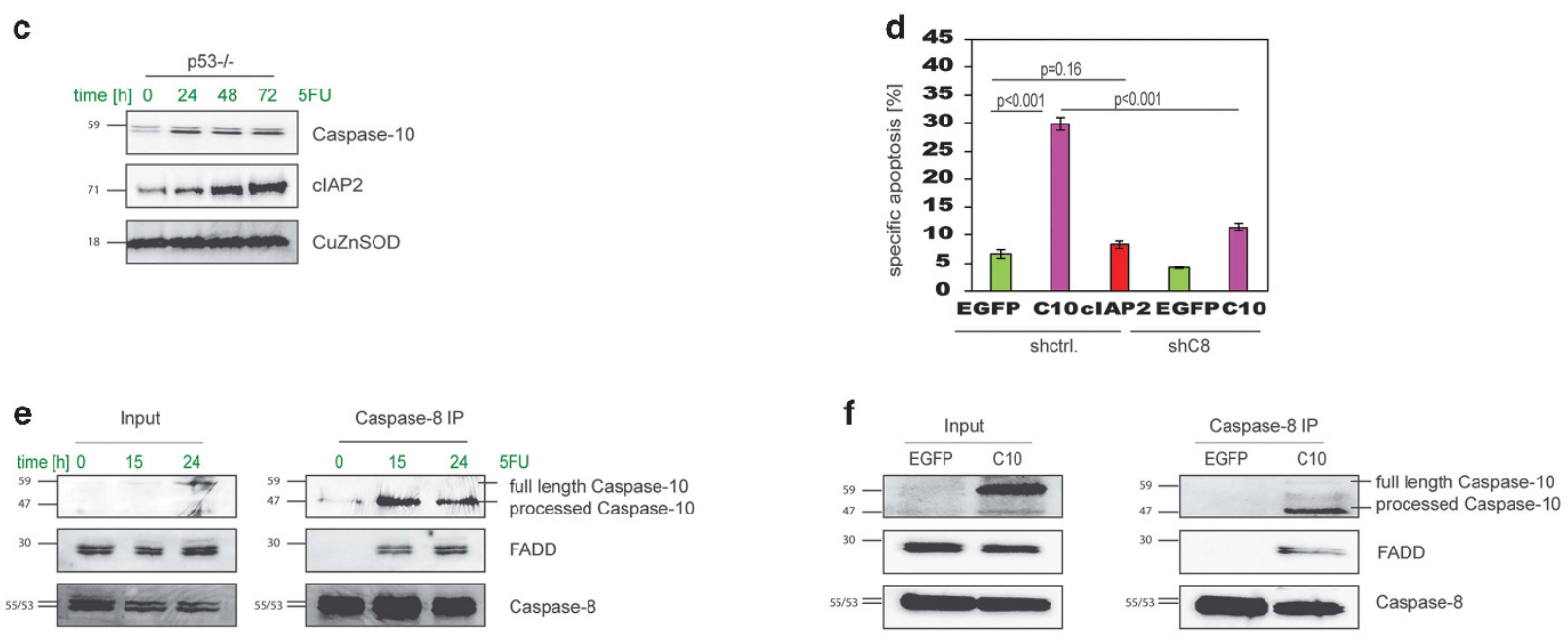

g
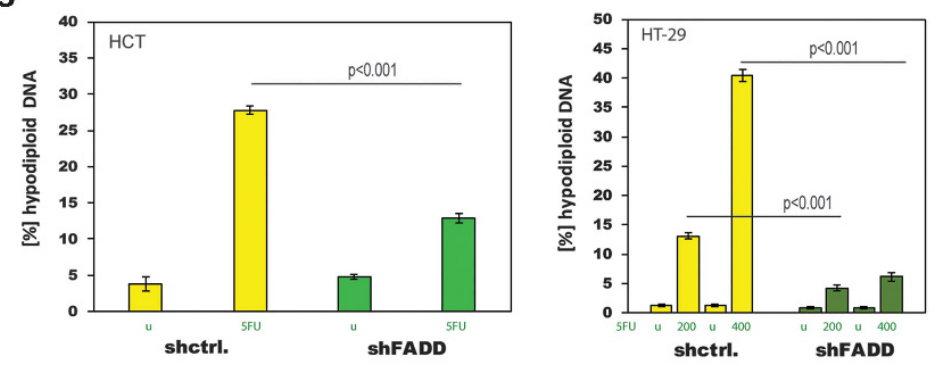

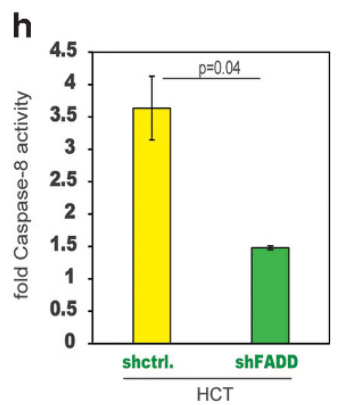

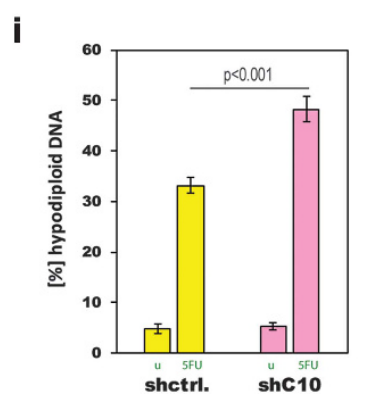

TNF- $a$ production, as both $c F L I P_{\mathrm{L}}$ and $\mathrm{CFLIP}_{\mathrm{p} 43}$, but not the cleavage-mutant $c F L I P_{D 376 N}$, were capable of turning on TNF- $a$ generation after 5FU treatment (Figure 4h). In contrast, silencing of CFLIP in HCT.shC10 cells gave rise to significantly reduced TNF- $a$ production in response to $5 \mathrm{FU}$ (Figure 4i). When we overexpressed $c F L I P L$ and $\mathrm{CFLIP}_{\mathrm{p} 43}$ in caspase-8 silenced cells we found that neither of the two was able to induce TNF- $a$ production demonstrating that 
Figure 3 Caspase-10 is upregulated in response to $5 F U$ and is part of a FADD and caspase- 8 containing complex. (a) Venn diagram of genes upregulated by $5 F U$ and a group of predicted caspase-8-interacting factors resulting in a union containing five genes. (b) Western blot for the identified factors after $5 F U$ treatment. (c) p53 - / - cells were treated with 5FU and analysed for caspase-10 and cIAP2 by western blot at the indicated time points. (d) Apoptosis levels following overexpression of caspase-10 and clAP2 in HCT.shctrl cells, and in addition of caspase-10 in HCT.shC8 cells. EGFP overexpression was used as control. Data are plotted as mean \pm S.E.M. ( $n \geq 3$ ). (e) Caspase-8 IP from HCT116 cells treated with 5FU. Complex formation was assessed by probing the caspase-8 precipitates for the presence of FADD and caspase- 10 by western blot. The panel on the left shows the input controls. (f) Caspase-8 IP from HCT116 cells overexpressing caspase-10. Complex formation was assessed by probing the caspase-8 precipitates for the presence of FADD and caspase-10 by western blot. Input controls are on the left. (g) FADD was knocked down in HCT116 and HT-29 cells (shFADD) and apoptosis was measured. HT-29.shFADD cells were treated with $200 \mu \mathrm{M}$ and $400 \mu \mathrm{M} 5 \mathrm{FU}$. Data are plotted as mean \pm S.E.M. $(n=3)$. (h) Caspase-8 activity following $5 \mathrm{FU}$ treatment was measured in HCT.shFADD cells. Data are plotted as mean \pm S.E.M. $(n=3)$. (i) Caspase-10 silenced HCT116 cells (shC10) were treated with $5 F U$ and analysed for apoptosis. Data are plotted as mean \pm S.E.M. $(n=7)$

caspase-8 activity was not only needed to cleave cFLIP , but also required as a platform to facilitate NF- $k B$ activation (Figure 4j). As for the prominent role of cFLIP in the complex triggering TNF-a production, we termed this complex FLIPosome consisting of caspase-8 and $\mathrm{CFLIP}_{\mathrm{L}}$ (Figure $4 \mathrm{k}$ ), whereas the caspase-8 activation complex in HCT116 cells was named FADDosome in recognition of the central role of FADD therein. To examine the utility of switching tumour cells to drug-induced TNF-a production as a sensitisation approach, we used HCT.shC10 cells in an in vivo study. We found that HCT.shC10 xenografts responded significantly better to 5FU than control xenografts (Figure $4 \mathrm{l}$ and Supplementary Figures $5 d$ and $5 e$ ).

TRAF2 is recruited to the FADDosome by caspase-10 and

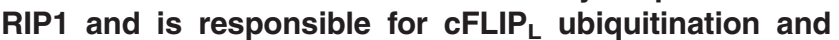
degradation. TNF- $a$ production and its involvement in apoptosis has been described in the context of other apoptosis-inducing mechanisms, for example, the action of IAP inhibitors or TNF- $a$-feedforward signalling. We were therefore interested whether these cell death mechanisms and complexes are comparable to the FLIPosome. Another key feature of these pathways and also the RIPoptosome is the degradation of IAPs, and indeed clAP1 was degraded in response to 5FU in caspase-10-silenced cells (Figure 5a). RIP1 has been described as a core and essential component of the mentioned apoptosis mechanisms. However, when we measured apoptosis in HCT.shC10.shRIP1 double knockdown cells, we did not observe diminished cell death, ruling out a role for RIP1 and the RIPoptosome (Figure 5b). Interestingly, we discovered that in single RIP1 knockdown cells (HCT.shRIP1) apoptosis was higher than in HCT.shctrl cells closely resembling HCT.shC10 cells (Figure 5b and Supplementary Figure 6a). Again, both clAP1 and $I_{\kappa} \mathrm{B}-a$ were degraded in HCT.shRIP1 cells and TNF- $a$ was produced in response to $5 \mathrm{FU}$, which could be inhibited by $\mathrm{I}_{k} \mathrm{~B}-\mathrm{SR}$ expression (Figure 5c and Supplementary Figure 6b). Hence, although RIP1 is not a critical factor for apoptosis, it is an essential factor for FADDosome formation, and RIP1 deficiency instead leads to the FLIPosome.

As we showed that proteolytic degradation of $C F L I P_{L}$ is a hallmark of the FADDosome, we set out next to identify the E3 ubiquitin ligase activity that binds within the FADDosome and initiates the proteolytic pathway. We analysed three candidate proteins, TRAF2, clAP1 and clAP2, which possess ubiquitin ligase activity and are known to be principally able to interact with FADDosome constituents. Co-IPs revealed that in addition to FADD and caspase-10, RIP1 and TRAF2 were bound to caspase- 8 after $5 \mathrm{FU}$ treatment (Figure $5 \mathrm{~d}$ ). This finding was strengthened by the fact that caspase- 8 activity could be precipitated with RIP1 (Supplementary Figure 6c). When we knocked down TRAF2 in HCT116 cells (HCT. shTRAF2) we detected, similarly to HCT.shC10 and HCT. shRIP1 cells, higher apoptosis levels in response to 5FU and TNF- $a$ production that could be blocked by IkB-SR (Figure $5 \mathrm{e}$ and Supplementary Figures $6 \mathrm{~d}$ and $6 \mathrm{e}$ ). Thus, the FADDosome was expanded by two additional factors, RIP1 and TRAF2. Furthermore, when we overexpressed TRAF2 we saw ubiquitination of $C F L I P_{L}$, which was absent in cells overexpressing a TRAF2- $\triangle$ RING variant lacking ubiquitin ligase activity as well as in cells overexpressing clAP1 or clAP2 (Figure $5 f$ and Supplementary Figure 6f). Similarly, we found $C F L I P_{L}$ degradation in 5FU-stimulated control HCT116 cells expressing either EGFP or TRAF2, but not in the TRAF2$\triangle \mathrm{RING}$ sample, which, acting in a dominant-negative manner, blocks CFLIP $\mathrm{L}_{\mathrm{L}}$ degradation (Figure $5 \mathrm{~g}$ ). These results demonstrate that TRAF2 is likely to be the ubiquitin ligase that is recruited to the FADDosome where it mediates cFLIP ubiquitination and degradation. In addition, RIP1 and caspase-10 are required for the TRAF2 recruitment and subsequent molecular processes and absence of any of the three factors leads to apoptosis through FLIPosome action instead.

ATR is essential for caspase-10 upregulation and FADDosome formation. Finally, we wondered how the cellular damage inflicted by cytotoxic drugs is translated into apoptosis signals inside the treated cells. Most chemotherapeutic drugs cause DNA damage, with 5FU additionally being able to give rise to perturbation in RNA metabolism. DNA damage activates the ATM and ATR kinases via autocatalytic phosphorylation. Once activated, they phosphorylate a plethora of proteins that control and repair DNA damage, but only very few direct molecular links to apoptosis induction have been established. When we checked for ATM and ATR activation in response to 5FU, we found only ATR to be phosphorylated, whereas with etoposide we obtained reverse results (Figure $6 \mathrm{a}$ and Supplementary Figure $7 \mathrm{a}$ ). Thus, we silenced ATR in HCT116 cells (HCT.shATR) (Supplementary Figure 7b) and also used the ATR inhibitor AZD6738 in combination with 5FU. When we measured apoptosis in these cells we discovered that both ATR silencing and AZD6738 caused significantly increased apoptosis (Figure 6b). An enzyme-linked immunosorbent assay (ELISA) of the supernatants of 5FU-stimulated HCT. shATR cells, as well as ATR inhibitor co-treated cells, 

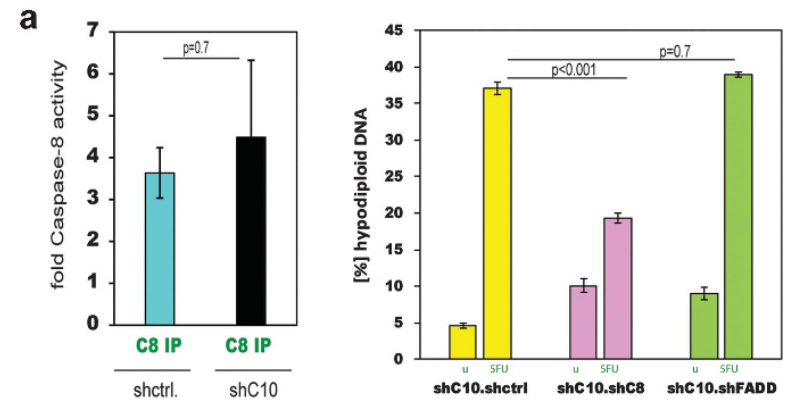

d
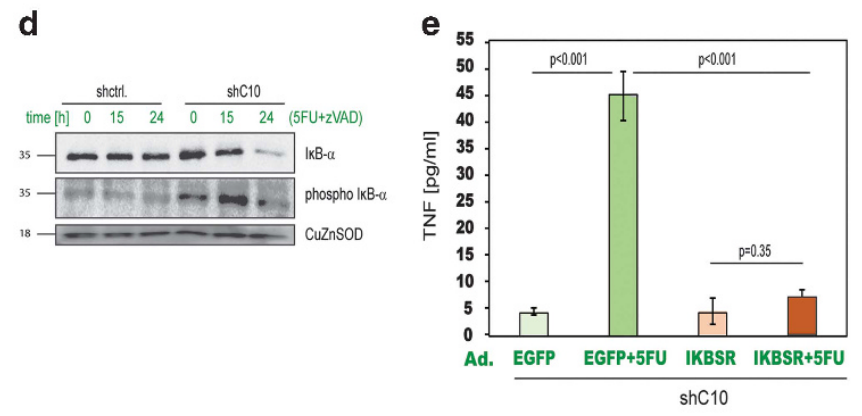
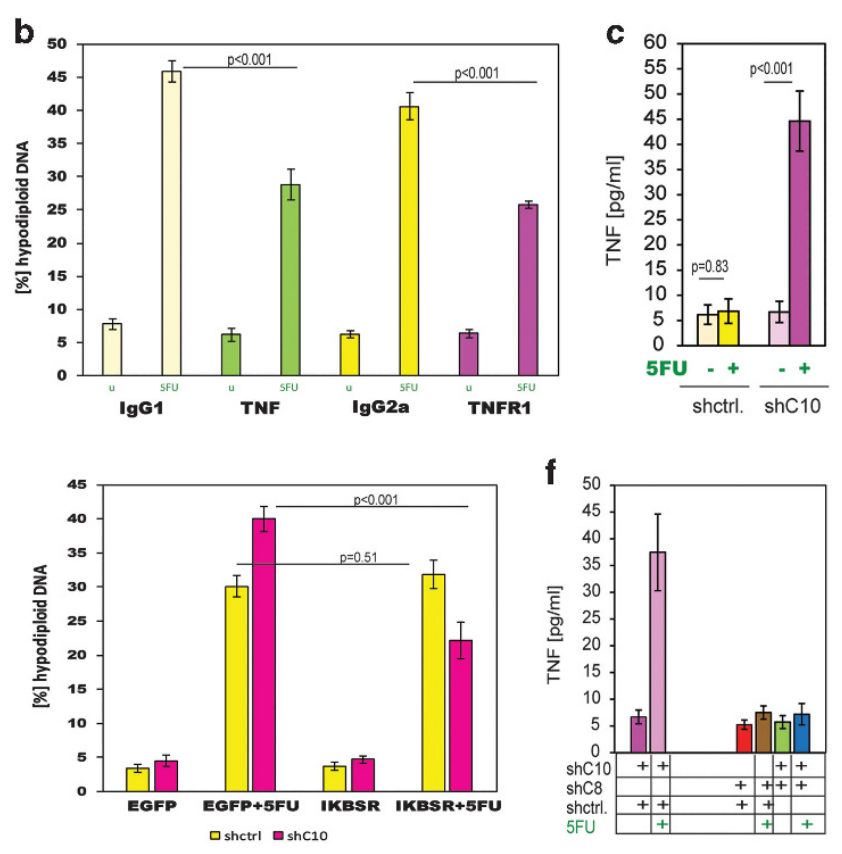

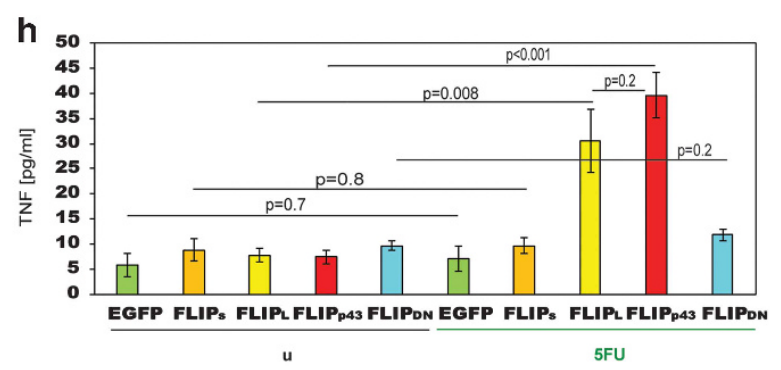

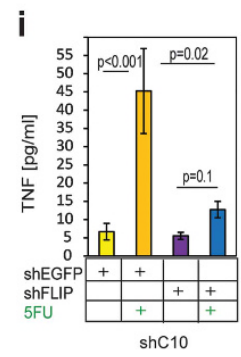

$\mathbf{k}$

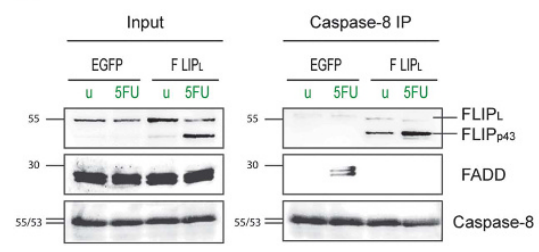

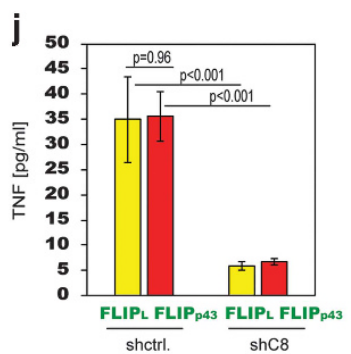

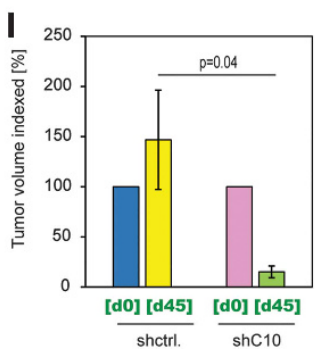

detected TNF- $a$ production, resembling the situation in HCT. shC10 cells. It appeared that cells lacking ATR activity engaged the FLIPosome to initiate apoptosis (Figure 6c). A subsequent western blot analysis revealed that caspase-10 was no longer upregulated in cells with knocked down or blocked ATR (Figure 6d). Furthermore, blocking ATR led to inhibition of Chk1 phosphorylation and p53 activation in response to 5FU (Figure 6d). Furthermore, we found 
Figure 4 Lack of Caspase-10 leads to TNF- $\alpha$ production in response to $5 F U$ and FADD-independent apoptosis. (a) (Left) Caspase-8 activity was measured in response to 5FU in HCT.shC10 cells. (Right) Double knockdown clones, HCT.shC10.shctrl, HCT.shC10.shC8 and HCT.shC10.shFADD were tested for apoptosis in response to 5FU. Data are plotted as mean \pm S.E.M. ( $n \geq 3$ ). (b) 5FU-induced apoptosis was measured in HCT.shC10 cells in the presence of TNF- $\alpha$ and TNFR1-blocking antibodies. IgG1 and lgG2a antibodies were used as isotype controls, respectively. Data are plotted as mean \pm S.E.M. $(n \geq 3)$. (c) TNF- $\alpha$ was measured in supernatants of 5FU-treated HCT.shC10 cells. Data are plotted as mean \pm S.E.M. $(n=3)$. (d) HCT.shC10 cells after 5 FU treatment were analysed by western blot for $I_{\kappa} \mathrm{B}-\alpha$ and phospho-I $\mathrm{B}$ - $\alpha$. (e) HCT.shC10 cells expressing IkB-SR (Ad.IkB-SR) were treated with 5FU, after which TNF- $\alpha$ and apoptosis were measured. Ad.EGFP served as control. Data are plotted as mean \pm S.E.M. ( $n \geq 3$ ). (f) HCT116 cells silenced for both caspase- 10 and caspase-8 were treated with $5 F U$ and TNF- $\alpha$ was measured. Data are plotted as mean \pm S.E.M. ( $n \geq 5$ ). (g) Western blot for cFLIP in HCT116 and HCT.shC10 cells after 5FU treatment. (h) EGFP, cFLIP , CFLIP , cFLIP 43 and cFLIP $P_{\mathrm{D} 36 \mathrm{~N}}\left(\mathrm{FLIP}_{\mathrm{DN}}\right)$ were expressed in HCT116 cells, and then the cells treated with $5 F U$ before TNF- $\alpha$ levels were measured. Data are plotted as mean \pm S.E.M. $(n \geq 2)$. (i) HCT.shC10 cells were silenced for cFLIP (Ad.shFLIP). TNF- $\alpha$ in cell culture supernatants was then determined after $5 \mathrm{FU}$ stimulation. Data are plotted as mean \pm S.E.M. $(n=2)$. (j) Either $c F L I P_{L}$ or $c F L I P_{p 43}$ were expressed in HCT.shC8 cells. After $5 F U$ treatment, TNF- $\alpha$ was measured. Data are plotted as mean \pm S.E.M. $(n \geq 3)$. (k) Precipitates from a caspase-8 IP were probed for cFLIP, FADD and caspase-8. The lysates were from HCT116 cells overexpressing CFLIP and treated with 5FU. Cells overexpressing EGFP were used as controls. Input controls are shown on the left. (I) End point tumour volumes of HCT.shC10 xenografts treated with 5FU are depicted in relation to starting volumes (set to 100). (animal numbers/group: $n=6 /$ shctrl, $n=3 /$ shC10].

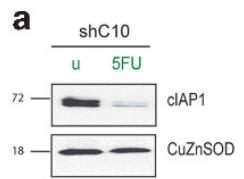

b

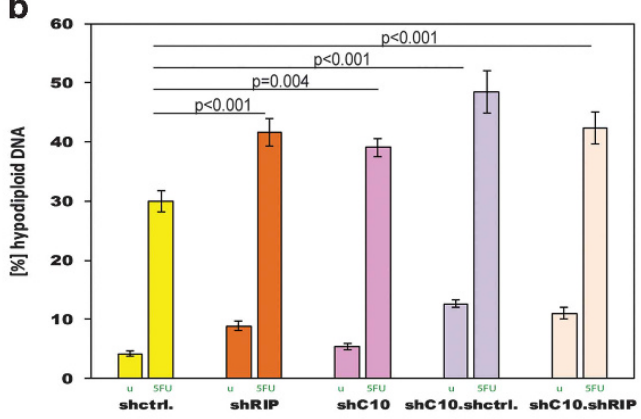

C

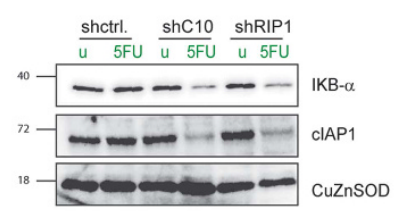

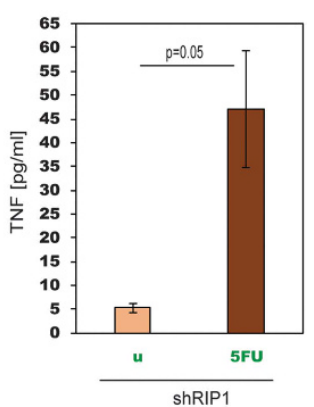
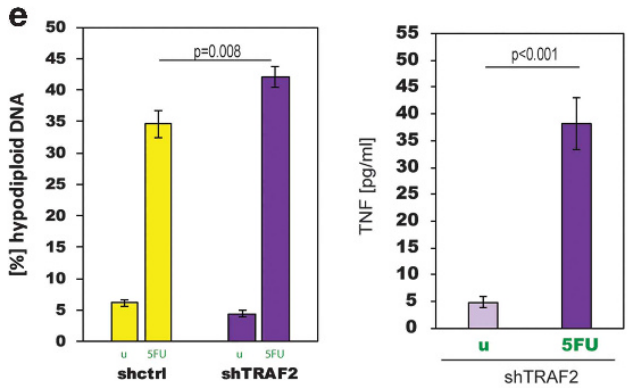
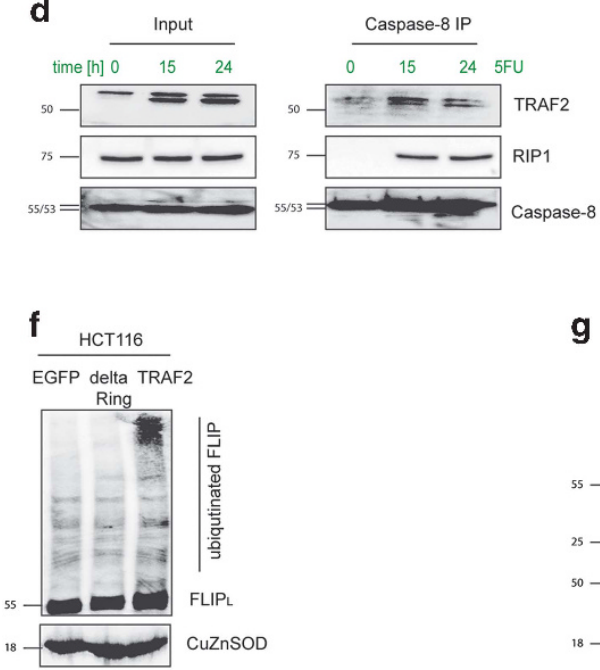

g

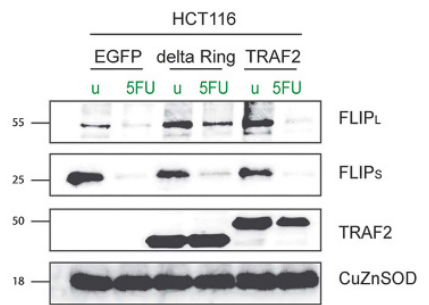

Figure 5 RIP1 and TRAF2 are dispensable for 5 FU-induced apoptosis, but required for FADDosome formation. (a) Western blot of protein lysates of $\mathrm{HCT}$.shC10 cells, treated with 5FU, probed with cIAP1 antibodies. (b) Apoptosis measurements after 5FU treatment of the following stable knockdown clones: HCT.shctrl, HCT.shRIP1, HCT.shC10, HCT. sC10.shctrl and HCT.shC10.shRIP1. Data are plotted as mean \pm S.E.M. ( $n \geq 3)$. (c) (Left) HCT.shctrl, HCT.shC10 and HCT.shRIP1 cells were treated with 5FU and the resulting protein lysates immuno-blotted and probed with $\mathrm{I}_{\kappa \mathrm{B}} \alpha$ and clAP1 antibodies. (Right) TNF- $\alpha$ was measured in HCT.shRIP1 cells treated with 5FU. Data are plotted as mean \pm S.E. M. $(n \geq 3)$. (d) Caspase-8 IP in 5FU-treated HCT116 cells. Resulting precipitates were analysed by western blot for RIP1, TRAF2 and caspase-8. Input controls are shown on the left. (e) (Left) Apoptosis measurements in HCT.shTRAF2 cells following 5FU treatment. (Right) TNF- $\alpha$ levels were measured in HCT.shTRAF2 cells treated with 5FU. Data are plotted as mean \pm S.E.M. $(n \geq 3)$. (f) EGFP, $\triangle$ RING-TRAF2 and TRAF2 were overexpressed in HCT116 cells and $24 \mathrm{~h}$ later the resulting protein extracts tested by Western blot for cFLIP. (g) Degradation of cFLIP was analysed in cells overexpressing EGFP, $\triangle$ RING-TRAF2 or TRAF2 following 5FU treatment. $\triangle$ RING-TRAF2 and TRAF2 expression is also shown.

the FLIPsome to act in a p53-independent manner (Supplementary Figures 7c-e) and that a specific thymidylate synthase inhibitor (Raltitrexed) could only give rise to FADDosome-mediated apoptosis, but was unable to trigger
TNF- $a$ production (Supplementary Figures 7f-h). These findings reveal a novel ATR-caspase-10 axis and also provide new insights into the mechanism of ATR inhibitors, such as AZD6738, in cancer treatment. 
a

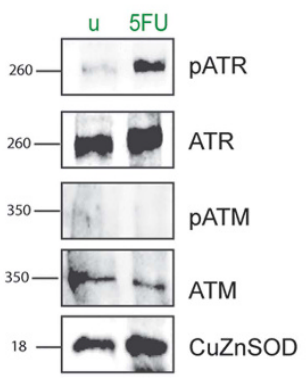

b

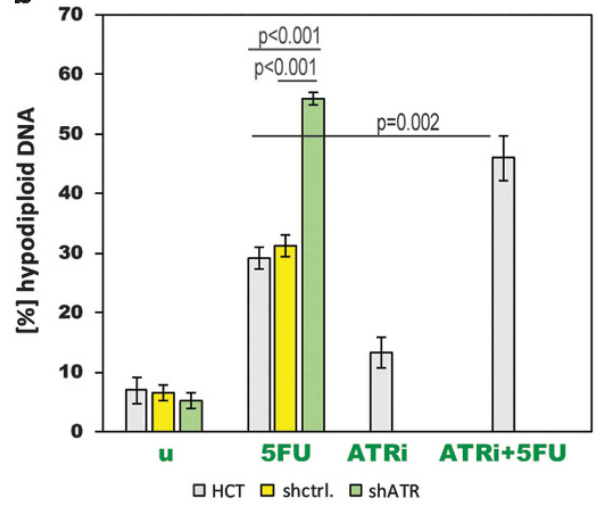

c

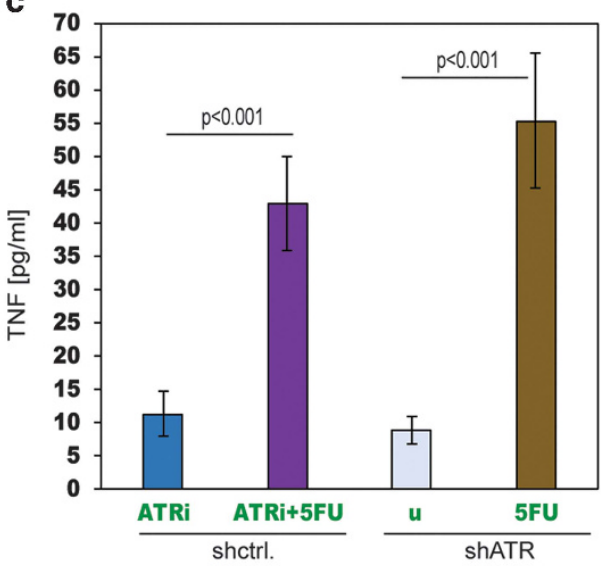

d
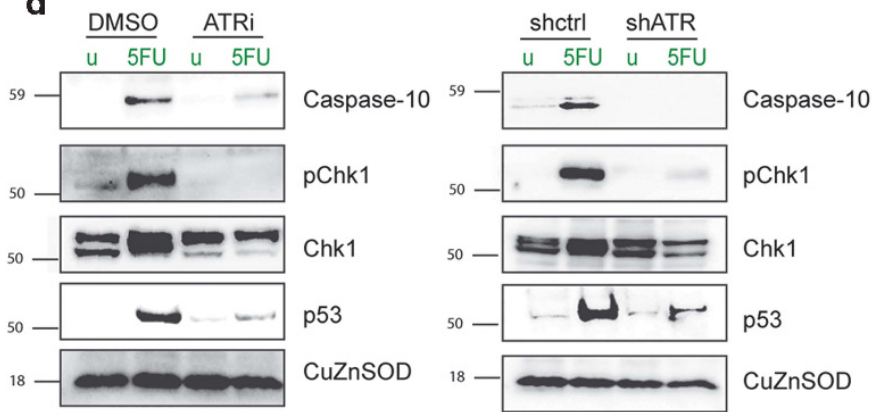

Figure 6 ATR is essential for caspase-10 upregulation and FADDosome formation. (a) Western blot analysing ATR and ATM phosphorylation in HCT116 cells treated with 5FU for $8 \mathrm{~h}$. (b) Apoptosis measurements in HCT116 cells treated with 5FU and a 5FU/ATR inhibitor combination, as well as HCT.shATR cells treated with 5FU. Data are plotted as mean \pm S.E.M. $(n \geq 3)$. (c) TNF- $\alpha$ measurements in HCT116 cells treated with 5FU and a 5FU/ATR inhibitor combination, as well as HCT.shATR cells treated with 5FU. Untreated HCT.shATR (u) are shown as controls. Data are plotted as mean \pm S.E.M. $(n \geq 4)$. (d) Western blots for caspase-10, phosphorylated Chk1, Chk1 and p53 in HCT116 cells treated with an ATR inhibitor (left) and HCT.shATR cells (right) treated with 5FU.

\section{Discussion}

Despite the evident importance of treatment-induced cell death induction in cancer cells, knowledge of the molecular steps that initiate and progress the apoptotic signalling cascade remain sketchy. However, a detailed understanding of the molecular event(s), leading to apoptosis is crucial for the development of improved diagnostic and predictive tools as well as novel therapeutic approaches.

We found that drugs that are known to give rise to replication stress and consequent single-strand DNA breaks lead to caspase-8 initiated apoptosis. These findings are in contrast to the consensus view that caspase- 9 initiates the apoptosis cascade in response to cytotoxic drugs and other intracellular stressors. $^{22,23}$ The observed caspase-8 activation was independent of death receptor triggering, in contrast to what was shown in the past for other cytotoxic drugs in different cancer cells. ${ }^{24,25}$ As RIP1 was also not essential for apoptosis, ruling out the RIPoptosome or TNF-a-feedforward signalling, we concluded that a novel caspase-8 mechanism must be responsible, for which our results suggest the following model (Figure 7). In response to treatment, ATR detects the drugproduced DNA lesions and elicits upstream signals that are responsible for the p53-independent caspase-10 upregulation. This provides the germ for the subsequent formation of the FADDosome, which aside from caspase-10, contains
FADD, caspase-8, RIP1 and TRAF2 (Figure 7a). Within the FADDosome, CFLIP is ubiquitinated by TRAF2 leading to its degradation. Interestingly, in the TRAIL DISC it is not CFLIP but its sibling molecule caspase- 8 that is ubiquitinated by TRAF2 pointing to context-specific activities and effects. ${ }^{26}$ Caspase-8, FADD, caspase-10, TRAF2 and also RIP1 as well as ATR are all required for FADDosome formation, with the latter four factors being dispensable for apoptosis. In the absence of these factors, cells switch to an alternative mechanism that involves a complex we termed FLIPosome and caspase-8-mediated cleavage of $\mathrm{CFLIP}$ to $\mathrm{CFLIP}_{\mathrm{p} 43}$ comparable to findings in the CD95 DISC ${ }^{27,28}$ (Figure $7 \mathrm{~b}$ ). This results in NF- $\kappa \mathrm{B}$ activation that drives expression of TNF- $a$, causing apoptosis in an autocrine and paracrine fashion. FLIPosome-induced apoptosis is, in contrast to the FADDosome, FADD- and p53-independent, providing distinct therapeutic advantages in solid tumours harbouring dysfunctional p53. The fact that both FADD as well as RIP1 are dispensable for the FLIPosome distinguishes it also from the RIPoptosome as well as the TNF- $a$-feedforward signalling pathway. ${ }^{14,16}$ Our results demonstrate that the FLIPosome is the more efficacious apoptosis mechanism as also evident by the increased $5 F U$ responsiveness in xenografts derived from caspase-10 silenced cells. Thus, flicking the switch from cell-autonomous apoptosis to non-autonomous cell death via the TNF- $a$ pathway provides a potential new avenue to overcome 
a

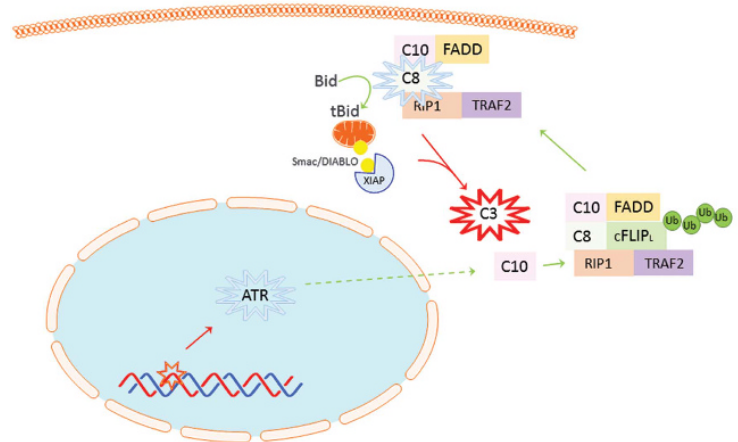

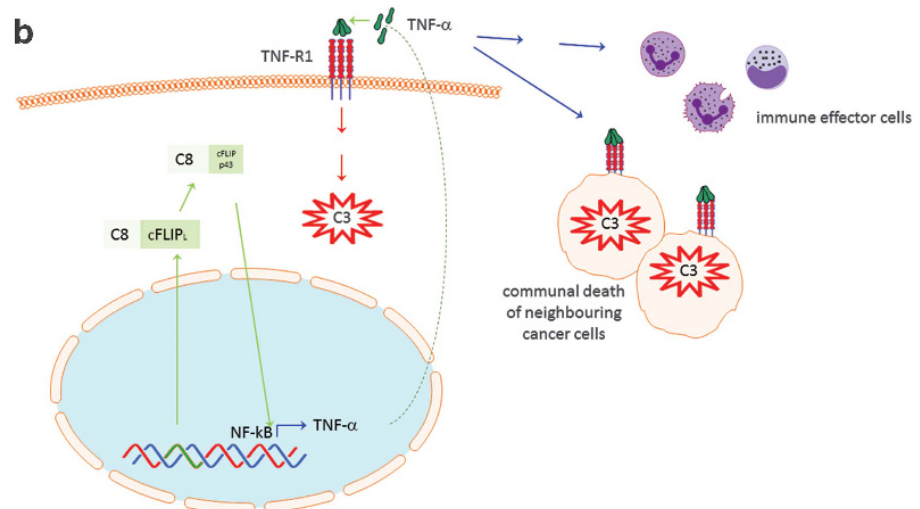

Figure 7 Model of cancer cell fate decisions following treatment. (a) Cell-autonomous cell death (FADDosome) as triggered by DNA single-strand breaks denoted by the 'red star'. (b) Communal cell death (FLIPosome) activated by incorporation of 5FU nucleotides into DNA/RNA or other damage types/repair mechanisms (symbolised by green DNA part).

resistance in tumour cells and/or increase treatment efficacy. The latter type of apoptosis, also known as 'communal death' normally has a role in tightly regulated developmental processes, which require a coordinated cell death response. ${ }^{29}$ It is a conserved mechanism found in flies and mammals that has also been implicated in the synchronous apoptosis wave observed in certain pathologies such as cardiac infarction and alcohol-/drug-induced liver failure. ${ }^{30-32}$ Our results indicate that tumour cells have either maintained or are able to reactivate this archaic pathway that is controlled by caspase-10. Our results regarding a regulatory but not directly apoptotic activity of caspase-10 are not dissimilar to findings about its role in the CD95 and TRAIL DISCs ${ }^{33}$ indicating a general role in orchestrating caspase-8 activation and cellular fate. Importantly, the caspase-10 gene has been shown to be lost in mice. ${ }^{34,35}$ As they are commonly used in the study of cancer treatments including apoptosis pathways, caution should be exercised when transferring results obtained in murine rodents to the human setting.

Our results also indicate a novel mode of action of ATR inhibitors when used in combination with other treatments as has been widely proposed. Owing to blocked DNA repair, such cells appear to respond with the more fulminate FLIPosome/ TNF- $a$-mediated cell death type including systemic antitumour functions of the immune system. These approaches also have the added advantage to be effective in p53-null cells. Having delineated the described apoptosis mechanisms and pathways offers several targets to interfere with and to engage at least one of the two different routes to apoptosis in order to bypass resistance points in cancer cells.

\section{Materials and Methods}

Reagents. All chemicals, unless otherwise stated, were purchased from Sigma (St. Louis, MO, USA). Pancaspase inhibitor zVAD.fmk (ZVAD) was from Santa Cruz Biotechnology (Santa Cruz, CA, USA) and biotinylated-VAD.fmk (bVAD) was bought from Calbiochem (Billerica, MA, USA). Recombinant CD95L was purchased from Enzo Life Sciences (Farmingdale, NY, USA). Recombinant TRAIL was purchased from R\&D Systems (Minneapolis, MN, USA). Recombinant TNF- $\alpha$ was purchased from Peprotech (Rocky Hill, NJ, USA). The ATR inhibitor AZD6738, raltitrexed and irinotecan were bought from Stratech (Newmarket, UK).
Antibodies. Sheep anti-CuZnSOD (The Binding Site, Birmingham, UK), goat and mouse anti-actin (Santa Cruz Biotechnology), rabbit anti-TRAlL-R2 (Cell Signaling Technology, Danvers, MA, USA), mouse anti-caspase-3 (Imgenex, Minneapolis, MN, USA), mouse anti-caspase-8 (Cell Signaling Technology, Santa Cruz Biotechnology and BD Biosciences, Franklin Lakes, NJ, USA), mouse antiXIAP (BD Biosciences), mouse anti-cFLIP (AdipoGen, San Diego, CA, USA), goat anti-cIAP1 (R\&D Systems), rat anti-clAP2 (Enzo Life Sciences), mouse anticaspase-9 (Novus Biologicals, Minneapolis, MN, USA), mouse anti-caspase-2 (BD Biosciences), mouse anti-CD178 (BD Biosciences), mouse anti-TNFR1 (Santa Cruz Biotechnology), rabbit anti-TRAIL (Peprotech), rabbit anti-TRAIL-R1 (Santa Cruz Biotechnology), mouse anti-TNFR1 (Hycult Biotech, Uden, Netherlands), mouse anti-FADD (Millipore, Billerica, MA, USA), rabbit anti-Bid (R\&D Systems), mouse anti-RIP1 (BD Biosciences), mouse anti-p53 (BD Biosciences), mouse anticaspase-10 (MBL, Woburn, MA, USA), rabbit anti-CD95 (Santa Cruz Biotechnology), mouse anti-TRAF2 (Santa Cruz Biotechnology), rabbit anti-TRADD (Cell Signaling Technology), rabbit anti-CRADD/RAIDD (Cell Signaling Technology), rabbit anti-NEMO (Santa Cruz Biotechnology), mouse anti-Myc (Santa Cruz Biotechnology), mouse anti-V5 (Thermo Fisher Scientific, Waltham, MA, USA), rabbit anti-IKB- $\alpha$ (Cell Signaling Technology), rabbit anti-Phospho-IKB- $\alpha$ (Cell Signaling Technology), rabbit anti-Phospho-ATR (GeneTex, Irvine, CA, USA), rabbit anti-ATR (Bethyl Laboratories, Montgomery, TX, USA), rabbit anti-Phospho-ATM (Cell Signaling Technology), mouse anti-ATM (Sigma), rabbit anti-Phospho-Chk1 (Cell Signaling Technology), mouse anti-Chk1 (Cell Signaling Technology), mouse anti-TNF- $\alpha$ (Biolegend, San Diego, CA, USA), IgG1 Isotype antibody (BD Biosciences), IgG2a Isotype antibody (Biolegend), IgG2b Isotype antibody (Biolegend), mouse anti-Smac/DIABLO antibody (Abcam, Cambridge, UK), FITCconjugated $F\left(a b^{\prime}\right) 2$ anti-mouse IgG2a antibody (Southern Biotechnology, Birmingham, AL, USA), FITC-conjugated F(ab)2 anti-mouse IgG2b antibody (Southern Biotechnology), mouse anti-cytochrome $c$ (BD Biosciences). Peroxidase-conjugated secondary antibodies were anti-mouse, anti-rabbit, anti-goat, anti-rat and anti-sheep (Santa Cruz Biotechnology). For co-immunoprecipitations TrueBlot peroxidaseconjugated secondary antibodies were used (Rockland, Limerick, PA, USA).

Cell lines. Human colorectal tumour HCT116 cells (ATCC, Manassas, VA, USA), their isogenic daughter cell line HCTp53 - / - (gift from Bert Vogelstein) and HT-29 (ATCC) cells were grown in McCoy's (Lonza, Basel, Switzerland) supplemented with 10\% FBS (Life Technologies, Waltham, MA, USA), $100 \mathrm{U} / \mathrm{ml}$ penicillin and $100 \mu \mathrm{g} /$ $\mathrm{ml}$ streptomycin. Human ovarian cancer cell line A2780 (Sigma) was grown in RPMl-1640 medium supplemented with $10 \% \mathrm{FBS}, 100 \mathrm{U} / \mathrm{ml}$ penicillin and $100 \mu \mathrm{g} /$ $\mathrm{ml}$ streptomycin. Human cervix carcinoma HeLa cells (ATCC) and human breast carcinoma MDA-MB-231 cells (ATCC) were grown in Dulbecco's modified eagle medium supplemented with $10 \% \mathrm{FBS}, 100 \mathrm{U} / \mathrm{ml}$ penicillin and $100 \mu \mathrm{g} / \mathrm{ml}$ streptomycin.

Overexpression constructs. Flag-clAP2/pRK5 was a gift from Xiaolu Yang (Addgene, Cambridge, MA, USA, plasmid \# 27973), ${ }^{36}$ pcdna3.1 hciap1 was a gift from Jon Ashwell (Addgene plasmid \# 8311) ${ }^{37} \mathrm{HA}$-Ubiquitin was a gift from Edward 
Yeh (Addgene plasmid \# 18712) ${ }^{38}$ Caspase-10 was purchased from Invivogen (San Diego, CA, USA). TRAF2, pCMV6.FADD.MYC and cFLIP were bought from Origene (Rockville, MD, USA). Generation of CFLIP constructs: $C F L I P L$ was cloned into pcDNA3.1/N5-His TOPO-TA (Life Technologies). cFLIP 43 was generated by PCR and cloned into pcDNA3.1/V5-His TOPO-TA (Life Technologies). The 3'-PCR primer contains a stop codon, so that the V5-His tag is not expressed. FLIP $P_{\mathrm{D} 376 \mathrm{~N}}$ was generated by site-directed mutagenesis of the $C F L I P_{L}$ construct using the QuikChange II Site-Directed Mutagenesis Kit (Agilent Technologies, Santa Clara, CA, USA). Generation of TRAF2 constructs: TRAF2 $\triangle$ Ring was generated by PCR and along full-length TRAF2 cloned into pcDNA3.1. Generation of FADD constructs: To obtain two differently tagged FADD constructs, FADD was also cloned into pcDNA3.1/V5-His TOPO-TA (Life Technologies) by PCR. The resulting construct was termed pcDNA.FADD.V5. Generated constructs were validated by sequencing.

Knockdown constructs and stable cell line generation. The following small hairpin (sh) RNA motifs were used to target XIAP (shXIAP), ${ }^{39}$ caspase-8 (shC8), ${ }^{40}$ caspase-2 (shC2) (5'-GACAGCTGTTGTTGAGCGAA-3'), caspase-10 (shC10) (5'-GCATTGACTCAGAGAACTTAA-3'), Bid (shBid), ${ }^{40}$ FADD (shFADD) (5'-GTGCAGCATTTAACGTCAT-3'), RIP1 (shRIP) (5'GCTGCTAAGTACCAAGCTATC- $3^{\prime}$ ), cFLIP (shFLIP), ${ }^{41}$ TRAF2 (shTRAF2), ${ }^{42}$ p53 (shp53), ${ }^{43}$ caspase-9 (shC9), ${ }^{44}$ EGFP (shEGFP), ${ }^{44}$ ATR (shATR), ${ }^{45}$ scrambled (shsc) (5'- GCGTAAGTCGCACGTCACACA-3'), Lamin A/C (shLamin) (Life Technologies). Sense and antisense oligos containing the short-hairpin sequence were hybridised to generate double-stranded DNA fragments. These fragments were then cloned into a modified pU6.ENTR plasmid (Life Technologies). The resulting pU6.ENTR plasmids were used to generate the pAd.sh plasmids using the LR Clonase II system (Life Technologies). Furthermore, the pU6.ENTR plasmids were used to generate the pBlockiT.sh plasmids (Life Technologies) to generate stable knock-downs. For this, the respective pBlockiT.sh plasmids were FuGene HD transfected into cells. Three days later, the transfected cells were split into Blasticidin containing selection medium. Arising clones were picked, transferred to 24-well plates and tested for gene silencing. Moreover, shLamin clones, which were generated by transfection with the pBlockiT6-GW/U6-lamin.shRNA plasmid, served as RNAi controls (Supplementary Figure S7b and S7b). To generate the shC10/ shFADD, shC10/shRIP1, shC10/shC8 and shC10/shp53 double knockdown clones, we generated shFADD, shRIP1, shC8 and shp53 RNAi plasmids in psiRNAh7SKzeo (InvivoGen). For this, we ligated the double-stranded DNA fragment, containing the respective motifs into the Bbsl- (Bpi1; Fisher Scientific) opened psiRNA-h7SKzeo vector. The resulting plasmids were FuGene HD transfected into HCT.shC10 cells. Following the same procedure as described above, the cells were selected in Zeocin (InvivoGen) containing medium. A clone generated with empty plasmids served as HCT.shctrl cells.

Generation of knockout cell lines via CRISPR/Cas9. Sequences of gRNAs were selected according to the Zhang lab. The respective gRNAs were inserted into the pX459 V2.0 plasmid as previously described. ${ }^{46} \mathrm{HCT} 116$ cells were transfected with the respective pX459 V2.0 gRNA plasmid. $24 \mathrm{~h}$ post transfection, positive cells were selected using puromycin prior to clonal expansion in normal growth medium. After 3-4 weeks, clones were screened for knockout by immunoblot.

Generation of adenoviral vectors and transduction. Adenoviral vectors expressing $c F L I P_{L}\left(A d . c F L I P_{L}\right)$ and dominant-negative caspase-9 (Ad.DNC9) were purchased from Vector Biolabs (Philadelphia, PA, USA). IKB-SR (Ad.IKBSR), DsRed (Ad.DsRed) and enhanced green fluorescent protein (EGFP; Ad. EGFP) were described previously. . $^{39,47,48}$ Adenoviral vectors encoding small hairpin constructs were generated using the ViraPower adenoviral expression system (Life Technologies). Adenoviral vectors encoding small hairpin constructs were targeted against EGFP, cFLIP, caspase-8, caspase-2, caspase-9, XIAP and p53 genes, respectively. The vectors were named Ad.shEGFP, Ad.shcFLIP, Ad.shC8, Ad.shC2, Ad.shC9, Ad.shXIAP and Ad.shp53. A vector expressing a scrambled shRNA (Ad. shsc) served as additional control. For adenoviral transduction, the normal growth medium was changed to medium with $2 \%$ FBS. The cells were transduced with virus at 200 pfu/cell for $6 \mathrm{~h}$ and then washed off.

Apoptosis measurements. To determine drug-induced cell death, cells were stimulated with $200 \mu \mathrm{M}$ 5FU (48 h), $50 \mu \mathrm{M}$ Raltitrexed (72 h), $10 \mu \mathrm{M}$ Irinotecan (48 h) or $100 \mu \mathrm{M}$ etoposide (48 h), respectively. The pancaspase inhibitor zVAD was used at $20 \mu \mathrm{M}$ and incubated for $4 \mathrm{~h}$ as pre-treatment before $5 \mathrm{FU}$ was added. DNA hypodiploidy staining: cells including their medium supernatant and PBS wash were harvested and centrifuged at $1300 \mathrm{rpm}$ for $7 \mathrm{~min}$ at $4{ }^{\circ} \mathrm{C}$. After washing with PBS, Nicoletti buffer (Sodium citrate $0.1 \%(\mathrm{w} / \mathrm{v})$ containing $0.1 \%$ Triton $\mathrm{X}-100(\mathrm{w} / \mathrm{v})$ and propidium iodide $50 \mu \mathrm{g} / \mathrm{ml})^{49}$ was added to the cell pellets, tubes were vortexed for $10 \mathrm{~s}$ at medium speed and left for $5 \mathrm{~h}$ in the dark $\left(4^{\circ} \mathrm{C}\right)$. The fluorescence intensity was then measured in a flow cytometer and analysed with the Venturi One software package (Applied Cytometry, Sheffield, UK). Normally, absolute apoptosis levels are depicted, but when specific apoptosis is shown, it was determined by subtraction of the basal apoptosis values from the cell death levels of treated cells. AnnexinV/PI staining. The AnnexinV/PI staining was carried out as follows: Cells were treated with $5 \mathrm{FU}$ and harvested $48 \mathrm{~h}$ later. Cells were then trypsinised and spun down at $1300 \mathrm{rpm}$ for $7 \mathrm{~min}$ at $4{ }^{\circ} \mathrm{C}$. Subsequently, cells were washed with binding buffer (10 mM HEPES NaOH (pH 7.4), $150 \mathrm{mM} \mathrm{NaCl}, 5 \mathrm{mM}$ $\mathrm{KCl}, 1 \mathrm{mM} \mathrm{MgCl}$, $1.8 \mathrm{mM} \mathrm{CaCl}_{2}$ ) and recentrifuged. The cell pellets were resuspended in binding buffer containing AnnexinV (Roche, Basel, Switzerland) at a final concentration of $2.5 \mu \mathrm{g} / \mathrm{ml}$ and incubated for $15 \mathrm{~min}$ at $4{ }^{\circ} \mathrm{C}$ in the dark. Shortly before the measurement, PI solution was added at a final concentration of $2 \mu \mathrm{g} / \mathrm{ml}$ in binding buffer prior to analysis.

Necrosis measurement. Loss of plasma membrane integrity: cells were harvested and washed in PBS, centrifuged at $1300 \mathrm{rpm}$ for $5 \mathrm{~min}$, and then resuspended in $100 \mu \mathrm{l}$ PBS. Shortly before FACS measurement, PI (to $2 \mu \mathrm{g} / \mathrm{ml}$ ) was added.

Clonogenic assay. HCT.shctrl and HCTshC8 cells were treated with $200 \mu \mathrm{M}$ $5 \mathrm{FU}$ for $15 \mathrm{~h}$ before 10000 cells were seeded in normal growth medium. After 3 weeks, resulting colonies were fixed in $2 \%$ paraformaldehyde (PFA) and visualised with a $0.04 \%$ crystal violet solution. Colonies were then counted.

Neutralising antibody and death ligand treatments. Cells were pretreated with the following antibodies: anti-CD178 (NOK1) $(25 \mu \mathrm{g} / \mathrm{ml})$, anti-TRAIL $(0.5 \mu \mathrm{g} / \mathrm{ml})$ and anti-TNF- $\alpha(10 \mu \mathrm{g} / \mathrm{ml})$ for $5 \mathrm{~h}$, followed by $5 \mathrm{FU}$ stimulation for $48 \mathrm{~h}$. The efficacy of the antibodies was tested by stimulating with their respective ligands. In this context, cells were pretreated as described above, before addition of the respective death ligands. CD95 L was used at a concentration of $250 \mathrm{ng} / \mathrm{ml}$ and TRAIL at a concentration of $5 \mathrm{ng} / \mathrm{ml}$ for $48 \mathrm{~h}$. Cells were pretreated with anti-TNFR1 antibody (Hycult Biotech) $(100 \mu \mathrm{g} / \mathrm{ml})$ for $24 \mathrm{~h}$, followed by $5 \mathrm{FU}$ and anti-TNFR1 cotreatment.

Measurement of the mitochondrial membrane potential. Perturbations in mitochondrial transmembrane potential were monitored by flow cytometry. Cells were treated with $200 \mu \mathrm{M} 5 \mathrm{FU}$ for $24 \mathrm{~h}$, or left untreated as control. Following drug treatment, cells were harvested and washed with prewarmed PBS. The cells were then labelled with $2 \mathrm{nM}$ DIOC6(3) (Thermo Fisher Scientific) at $37^{\circ} \mathrm{C}$ for 20 min and subsequently analysed by FACS.

Cytochrome c measurements. HCT116 cells were either pretreated with $20 \mu \mathrm{M} \mathrm{zVAD}$ for $4 \mathrm{~h}$ or left untreated before $5 \mathrm{FU}$ was added for $48 \mathrm{~h}$. FACS analysis of cytochrome $\mathrm{c}$ release was performed according to a previously described protocol. ${ }^{50}$ Cytochrome $c$ release is detected as a drop in the fluorescent signal.

Smac/DIABLO release. HCT116 cells were either pretreated with $20 \mu \mathrm{M}$ zVAD for $4 \mathrm{~h}$ or left untreated before 5FU was added for $48 \mathrm{~h}$, harvested and prefixed with $0.01 \%$ PFA for $20 \mathrm{~min}$ at $4{ }^{\circ} \mathrm{C}$. Prefixation was followed by an additional fixation step with $0.12 \%$ PFA for $20 \mathrm{~min}$ before the cells were permeabilised with $0.1 \%$ Saponin for $5 \mathrm{~min}$ at $4^{\circ} \mathrm{C}$. Next, mouse IgG1 was added $\left(50 \mu \mathrm{g} / \mathrm{ml}\right.$ ) for $20 \mathrm{~min}$ at $4^{\circ} \mathrm{C}$, followed by $1 \mu \mathrm{g} / \mathrm{ml}$ anti-Smac/DIABLO antibody for an additional $20 \mathrm{~min}$ at $4^{\circ} \mathrm{C}$. IgG2a isotype antibody was used as control. For Smac/DIABLO staining, the cells were incubated with FITC-conjugated goat $F\left(a b^{\circ}\right)_{2}$ anti-mouse IgG2a antibody (1:20) for $20 \mathrm{~min}$ at $4^{\circ} \mathrm{C}$ in the dark. Samples were then analysed by FACS. Smac/DIABLO release is detected as an increase in the fluorescent signal.

Western blot. Proteins were separated by SDS-PAGE and transferred onto PVDF membranes (GE Healthcare Biosciences, Piscataway, NJ, USA). Primary and secondary antibodies were diluted in TBS, $0.1 \%$ Tween and $3 \%$ BSA. Bands were visualised with ECL Western blotting substrate (Thermo Fisher Scientific). CuZnSOD served as loading control. 
TNF- $\alpha$ ELISA. To examine TNF- $\alpha$ levels, we plated $1 \times 10^{7}$ cells in a $15 \mathrm{~cm}$ dish We transduced or transfected the cells $24 \mathrm{~h}$ before $5 \mathrm{FU}$ stimulation. Cells were stimulated with $100 \mu \mathrm{M} 5 \mathrm{FU}$ for $24 \mathrm{~h}$ before medium was exchanged to zVAD $(20 \mu \mathrm{M})$ containing serum-free medium (UltraCULTURE, Lonza). After $72 \mathrm{~h}$ cell culture supernatants were cleared and concentrated fivefold. For concentrating of supernatants we used Amicon Ultra-centrifugal Filters ( $3 \mathrm{kDa})$. A commercial TNF- $\alpha$ ELISA Kit (R\&D Systems) was used following the manufacturer's instructions.

Cytokine array. For these studies, we took blood from two mice of each treatment group at the end of each experiment and separated serum from whole blood. The respective sera were diluted 1:5 and applied to mouse cytokine antibody arrays III (RayBio, Norcross, GA, USA) according to manufacturer's instructions. We normalised each cytokine signal to its internal control and compared each treatment group (PBS- treated HCT.shctrl animals with PBS treated HCT.shC10 animals (PBS) and 5FU-treated HCT.shctrl animals with 5FU-treated HCT.shC10 animals $(5 \mathrm{FU}))$ with each other and expressed changes in caspase- 10 silenced xenografts in different colours. We used a two colour scale from green ( $\leq 1.5$-fold change) to red ( $\geq 5$-fold change)

Sucrose density gradient fractionation. The sucrose gradient protocol was adapted from Feig et al. ${ }^{51}$ In brief, cells were treated with $5 \mathrm{FU}$ for $24 \mathrm{~h}$ before they were harvested, washed once with ice-cold PBS and resuspended in $1 \%$ Triton X-100 buffer (30 mM Tris-HCl [pH 7.5]; $150 \mathrm{mM} \mathrm{NaCl;} 2.5 \mathrm{mM}$ EDTA; 10\% (v/v) glycerol; $1 \%$ (v/v) Triton X-100; protease inhibitors). Cell lysis was carried out for $10 \mathrm{~min}$ on ice and lysates were cleared of debris by centrifugation at $14000 \mathrm{rpm}$ for $10 \mathrm{~min}$ at $4{ }^{\circ} \mathrm{C}$. The protein lysate $(1.5 \mathrm{mg})$ was overlaid on top of the sucrose gradient (10-50\% (w/w) sucrose), which was then subjected to ultracentrifugation at $37500 \mathrm{rpm}$ for $16 \mathrm{~h}$. Fourteen equal fractions were then collected and subjected to SDS-PAGE and western blotting for proteins of interest.

Immunoprecipitation experiments. Cells were plated overnight and stimulated with 5FU for $24 \mathrm{~h}$ unless otherwise indicated. Cells were collected, washed in ice-cold PBS, and lysed in the appropriate immunoprecipitation buffer containing protease inhibitor cocktail tablets (Roche). For the caspase-8 immunoprecipitation, cells were lysed in NP-40 buffer (50 mM Tris (pH 7.4); $10 \%$ glycerol; $0.5 \% \mathrm{NP}-40 ; 150 \mathrm{mM} \mathrm{NaCl} ; 1 \mathrm{mM} \mathrm{MgCl} ; 1 \mathrm{mM} \mathrm{CaCl} ; 1 \mathrm{mM} \mathrm{KCl}$; protease inhibitors). The caspase-8 antibody (Santa Cruz Biotechnology) was used at a concentration of $1 \mu \mathrm{g} / \mathrm{mg}$ protein and cross-linked to Protein $\mathrm{A} / \mathrm{G}$ agarose (Pierce Crosslink IP Kit, Thermo Fisher Scientific). For the Myc-tag immunoprecipitation, cells were plated overnight and followed by co-transfection with pCMV6. FADD.MYC and pcDNA.FADD.V5 expression plasmids at equal amounts of DNA. $5 \mathrm{~h}$ post transfection, the medium was changed and after an additional $5 \mathrm{~h}$, cells were stimulated with $5 \mathrm{FU}$ for $15 \mathrm{~h}$. Cells were treated with etoposide $(150 \mu \mathrm{M}) 12 \mathrm{~h}$ after the change of medium for another $15 \mathrm{~h}$. Untreated transfected cells served as controls. Cells were lysed in RIPA buffer (50 mM Tris-HCl [pH 7.4]; $150 \mathrm{mM} \mathrm{NaCl}$; 2 mM EDTA; $1 \%$ NP-40; 0.1\% SDS; protease inhibitors). The Myc antibody was used at a concentration of $1 \mu \mathrm{g} / \mathrm{mg}$ protein and captured with magnetic beads precoated with anti-mouse antibodies.

For the RIP1, caspase-8 and actin immunoprecipitations used in the caspase-8 activity assays, cells were lysed in NP-40 buffer. The antibodies were used at a concentration of $1 \mu \mathrm{g} / \mathrm{mg}$ protein and captured with Protein A/G agarose (caspase-8 and actin IP) or magnetic beads pre-coated with anti-mouse antibodies (RIP1 and actin IP).

Caspase-8 activity assay. Caspase- 8 activity was measured after caspase8 , actin and RIP1 immunoprecipitations, respectively. The caspase-8 and RIP1 immunoprecipitations were performed as described above with one additional wash with cold aqua bidest included after the magnetic beads were washed five times with lysis buffer. Finally, the beads were resuspended in $100 \mu$ l aqua bidest followed by addition of $100 \mu \mathrm{l}$ of Caspase-8 Glo buffer (Promega, Madison, WN, USA). Luminescent readings were carried out and samples were analysed after $1 \mathrm{~h}$.

In-situ trapping and streptavidin-precipitation of biotinylated initiator caspases. This method was performed according to a previously described protocol. ${ }^{52}$ Cells were pretreated with $50 \mu \mathrm{M}$ bVAD for $2 \mathrm{~h}$ in their normal growth medium and under normal culture conditions before 5FU was added. After 5FU stimulation $(18 \mathrm{~h})$, cells were harvested and protein lysates prepared as described previously. ${ }^{7}$ These protein lysates were subsequently mixed with streptavidin-conjugated magnetic beads (Thermo Fisher Scientific) and incubated for $16 \mathrm{~h}$. The beads were then washed six times with lysis buffer before they were resuspended in Laemmli loading buffer.

Ubiquitination analysis. HCT116 cells were transfected with $2 \mu \mathrm{g}$ of the pcDNA.cFLIPL expression vector, $2 \mu \mathrm{g}$ of the pcDNA.HA-Ubiquitin plasmid and $2 \mu \mathrm{g}$ of either the CIAP1, CIAP2 or TRAF2 expression constructs. After $24 \mathrm{~h}$ of the transfection, MG132 $(10 \mu \mathrm{M})$ was added to the cells. Four hours later, the cells were lysed under denaturing conditions with hot lysis buffer $\left(95^{\circ} \mathrm{C}\right)$ containing $1 \%$ SDS, $1 \mathrm{mM}$ EDTA and $50 \mathrm{nM} \mathrm{NaF}$. The lysates were then diluted (1:5) with cell lysis buffer. Cleared, diluted lysates were analysed on a $6 \%$ SDS-PAGE/western blot for cFLIP ubiquitination.

Animal studies. Ten weeks old female CD1 nu/nu mice (Harlan, Indianapolis, IN, USA) were injected with $5 \times 10^{6}$ cells in $200 \mu$ l PBS. After 10 days and when tumours were palpable the animals were intraperitoneally injected with $5 \mathrm{FU}$ $(150 \mathrm{mg} / \mathrm{kg}$ ) once a week over 4 weeks. The growth of the tumours was followed over 45 days. The tumour volume was calculated using three different diameters and the formula: $\pi / 6^{*}\left(\mathrm{~d} 1^{*} \mathrm{~d} 2^{*} \mathrm{~d} 3\right)$. The animal studies were performed according to national laws and were covered by a license.

Histological analyses. Tumour samples taken during necropsy were fixed in $10 \%$ neutral-buffered formalin, paraffin embedded and $4-\mu \mathrm{m}$ sections were stained with hematoxylin and eosin (H\&E).

RNA isolation and RNA-Seq. Cells were treated with $5 \mathrm{FU}$ for $24 \mathrm{~h}$. Total RNA was isolated using TRIZOL (Life Technologies). cDNA library preparation and sequencing was performed on an Illumina HiSeq 2500 by GATC Biotech (Konstanz, Germany). Sequence data quality control was evaluated using the FastQC programme on the Galaxy platform (http://galaxyproject.org/). Reads were aligned to the UCSC hg19 human reference genome using Tophat2. Cufflinks was used to reconstruct the transcriptome and differentially expressed genes were identified with Cuffdiff. All analyses were performed using the Galaxy platform. Genes that were found to be upregulated in response to $24 \mathrm{~h} 5 \mathrm{FU}$ treatment were compared with predicted functional partners of caspase-8 (Supplementary File S8).

Statistical analysis. Experimental values are expressed as mean value \pm standard error (S.E.M.). For significance analyses, analysis of variance between groups was used.

\section{Conflict of Interest}

The authors declare no conflict of interest.

Acknowledgements. We thank Greg Brooke for helpful discussions and Jigyasa Arora, Alex Menzies, Alice Godden, Rui Yu, Chirlei Klein for technical assistance and John Norton for support with the RNA-Seq experiment. RMZ was supported by an Emmy-Noether grant (ZW60/2), a Marie-Curie Excellence grant (MIST) and an RTN grant (ApopTrain).

\section{Author contributions}

AM, LD, SJ, YM, LH, SMA performed experiments; AM and RMZ conceived and designed this study; analysed and interpreted data; wrote the manuscript. All authors read and approved the final manuscript.

1. Brown JM, Attardi LD. The role of apoptosis in cancer development and treatment response. Nat Rev Cancer 2005; 5: 231-237.

2. Green DR, Evan GI. A matter of life and death. Cancer Cell 2002; 1: 19-30.

3. Schneider P, Tschopp J. Apoptosis induced by death receptors. Pharm Acta Helv 2000; 74 : 281-286.

4. Fulda S, Debatin KM. Targeting apoptosis pathways in cancer therapy. Curr Cancer Drug Targets 2004; 4: 569-576.

5. Bratton SB, MacFarlane M, Cain K, Cohen GM. Protein complexes activate distinct caspase cascades in death receptor and stress-induced apoptosis. Exp Cell Res 2000; 256: 27-33.

6. Marsden VS, O'Connor L, O'Reilly LA, Silke J, Metcalf D, Ekert PG et al. Apoptosis initiated by $\mathrm{Bcl}-2$-regulated caspase activation independently of the cytochrome $\mathrm{c} /$ Apaf- $1 /$ caspase- 9 apoptosome. Nature 2002; 419: 634-637.

7. Tu S, McStay GP, Boucher LM, Mak T, Beere HM, Green DR. In situ trapping of activated initiator caspases reveals a role for caspase-2 in heat shock-induced apoptosis. Nat Cell Biol 2006; 8: 72-77. 
8. Wesselborg S, Engels IH, Rossmann E, Los M, Schulze-Osthoff K. Anticancer drugs induce caspase-8/FLICE activation and apoptosis in the absence of CD95 receptor/ligand interaction. Blood 1999; 93: 3053-3063.

9. Lassus $P$, Opitz-Araya $X$, Lazebnik $Y$. Requirement for caspase-2 in stress-induced apoptosis before mitochondrial permeabilization. Science 2002; 297: 1352-1354.

10. Sohn D, Schulze-Osthoff K, Janicke RU. Caspase-8 can be activated by interchain proteolysis without receptor-triggered dimerization during drug-induced apoptosis. J Bio Chem 2005; 280: 5267-5273.

11. Petersen SL, Wang L, Yalcin-Chin A, Li L, Peyton M, Minna J et al. Autocrine TNFalpha signaling renders human cancer cells susceptible to Smac-mimetic-induced apoptosis. Cancer Cell 2007; 12: 445-456.

12. Varfolomeev E, Blankenship JW, Wayson SM, Fedorova AV, Kayagaki N, Garg P et al. IAP antagonists induce autoubiquitination of C-IAPs, NF-kappaB activation, and TNFalphadependent apoptosis. Cell 2007; 131: 669-681.

13. Vince JE, Wong WW, Khan N, Feltham R, Chau D, Ahmed AU et al. IAP antagonists target CIAP1 to induce TNFalpha-dependent apoptosis. Cell 2007; 131: 682-693.

14. Tenev T, Bianchi K, Darding M, Broemer M, Langlais C, Wallberg F et al. The Ripoptosome, a signaling platform that assembles in response to genotoxic stress and loss of IAPs. Mol Cell 2011; 43: 432-448.

15. Feoktistova M, Geserick P, Kellert B, Dimitrova DP, Langlais C, Hupe M et al. clAPs block Ripoptosome formation, a RIP1/caspase-8 containing intracellular cell death complex differentially regulated by cFLIP isoforms. Mol Cell 2011; 43: 449-463.

16. Biton S, Ashkenazi A. NEMO and RIP1 control cell fate in response to extensive DNA damage via TNF-alpha feedforward signaling. Cell 2011; 145: 92-103.

17. Sun XM, MacFarlane M, Zhuang J, Wolf BB, Green DR, Cohen GM. Distinct caspase cascades are initiated in receptor-mediated and chemical-induced apoptosis. J Biol Chem 1999; 274: 5053-5060.

18. Tepper AD, de Vries E, van Blitterswijk WJ, Borst J. Ordering of ceramide formation, caspase activation, and mitochondrial changes during CD95- and DNA damage-induced apoptosis. $J$ Clin Invest 1999; 103: 971-978.

19. Ciccia A, Elledge SJ. The DNA damage response: making it safe to play with knives. Mol Cell 2010; 40: 179-204

20. Ando K, Kernan JL, Liu PH, Sanda T, Logette E, Tschopp J et al. PIDD death-domain phosphorylation by ATM controls prodeath versus prosurvival PIDDosome signaling. Mo Cell 2012; 47: 681-693

21. Bunz F, Hwang PM, Torrance $C$, Waldman T, Zhang Y, Dillehay L et al. Disruption of p53 in human cancer cells alters the responses to therapeutic agents. J Clin Invest 1999; 104: 263-269.

22. Hakem R, Hakem A, Duncan GS, Henderson JT, Woo M, Soengas MS et al. Differentia requirement for caspase 9 in apoptotic pathways in vivo. Cell 1998; 94: 339-352.

23. Kuida K, Haydar TF, Kuan CY, Gu Y, Taya C, Karasuyama H et al. Reduced apoptosis and cytochrome c-mediated caspase activation in mice lacking caspase 9. Cell 1998; 94 325-337.

24. Friesen C, Herr I, Krammer PH, Debatin KM. Involvement of the CD95 (APO-1/FAS) receptor/ligand system in drug-induced apoptosis in leukemia cells. Nat Med 1996; 2 : 574-577.

25. Olsson M, Vakifahmetoglu H, Abruzzo PM, Hogstrand K, Grandien A, Zhivotovsky B. DISCmediated activation of caspase-2 in DNA damage-induced apoptosis. Oncogene 2009; 28 1949-1959.

26. Gonzalvez F, Lawrence D, Yang B, Yee S, Pitti R, Marsters S et al. TRAF2 Sets a threshold for extrinsic apoptosis by tagging caspase-8 with a ubiquitin shutoff timer. Mol Cell 2012; 48 888-899.

27. Matsuda I, Matsuo K, Matsushita Y, Haruna Y, Niwa M, Kataoka T. The C-terminal domain of the long form of cellular FLICE-inhibitory protein (c-FLIPL) inhibits the interaction of the caspase 8 prodomain with the receptor-interacting protein 1 (RIP1) death domain and regulates caspase 8-dependent nuclear factor kappaB (NF-kappaB) activation. J Biol Chem 2014; 289: 3876-3887.

28. Kataoka T, Tschopp J. N-terminal fragment of c-FLIP $(L)$ processed by caspase 8 specifically interacts with TRAF2 and induces activation of the NF-kappaB signaling pathway. Mol Cell Biol 2004; 24: 2627-2636.
29. Suzanne M, Steller H. Shaping organisms with apoptosis. Cell Death Differ 2013; 20: $669-675$.

30. Guicciardi ME, Gores GJ. Apoptosis: a mechanism of acute and chronic liver injury. Gut 2005; 54: 1024-1033.

31. Kang PM, Izumo S. Apoptosis in heart: basic mechanisms and implications in cardiovascular diseases. Trends Mol Med 2003; 9: 177-182.

32. Perez-Garijo A, Fuchs $Y$, Steller H. Apoptotic cells can induce non-autonomous apoptosis through the TNF pathway. Elife 2013; 2: e01004.

33. Sprick MR, Rieser E, Stahl H, Grosse-Wilde A, Weigand MA, Walczak H. Caspase-10 is recruited to and activated at the native TRAIL and CD95 death-inducing signalling complexes in a FADD-dependent manner but can not functionally substitute caspase-8. EMBO J 2002; 21: $4520-4530$.

34. Eckhart L, Ballaun C, Hermann M, VandeBerg JL, Sipos W, Uthman A et al. Identification of novel mammalian caspases reveals an important role of gene loss in shaping the human caspase repertoire. Mol Biol Evol 2008; 25: 831-841.

35. Janicke RU, Sohn D, Totzke G, Schulze-Osthoff K. Caspase-10 in mouse or not? Science 2006; 312: 1874.

36. Hu S, Du MQ, Park SM, Alcivar A, Qu L, Gupta S et al. clAP2 is a ubiquitin protein ligase for $\mathrm{BCL} 10$ and is dysregulated in mucosa-associated lymphoid tissue lymphomas. J Clin Invest 2006; 116: 174-181.

37. Li X, Yang Y, Ashwell JD. TNF-RII and c-IAP1 mediate ubiquitination and degradation of TRAF2. Nature 2002; 416: 345-347.

38. Kamitani T, Kito K, Nguyen HP, Yeh ET. Characterization of NEDD8, a developmentally down-regulated ubiquitin-like protein. J Biol Chem 1997; 272: 28557-28562.

39. Mohr A, Albarenque SM, Deedigan L, Yu R, Reidy M, Fulda S et al. Targeting of XIAP combined with systemic mesenchymal stem cell-mediated delivery of STRAIL ligand inhibits metastatic growth of pancreatic carcinoma cells. Stem Cells 2010; 28: 2109-2120.

40. Wagner KW, Engels IH, Deveraux QL. Caspase-2 can function upstream of bid cleavage in the TRAIL apoptosis pathway. J Biol Chem 2004; 279: 35047-35052.

41. Song JH, Bellail A, Tse MC, Yong VW, Hao C. Human astrocytes are resistant to Fas ligand and tumor necrosis factor-related apoptosis-inducing ligand-induced apoptosis. J Neurosci 2006; 26: 3299-3308.

42. Hauer J, Puschner S, Ramakrishnan P, Simon U, Bongers M, Federle C et al. TNF receptor (TNFR)-associated factor (TRAF) 3 serves as an inhibitor of TRAF2/5-mediated activation of the noncanonical NF-kappaB pathway by TRAF-binding TNFRs. Proc Natl Acad Sci USA 2005; 102: 2874-2879.

43. Brummelkamp TR, Bernards R, Agami R. A system for stable expression of short interfering RNAs in mammalian cells. Science $2002 \% 19$ 296: 550-553.

44. Mohr A, Buneker C, Gough RP, Zwacka RM. MnSOD protects colorectal cancer cells from TRAIL-induced apoptosis by inhibition of Smac/DIABLO release. Oncogene 2008; 27: 763-774.

45. Ariumi $Y$, Turelli $P$, Masutani M, Trono D. DNA damage sensors ATM, ATR, DNA-PKcs, and PARP-1 are dispensable for human immunodeficiency virus type 1 integration. J Virol 2005; 79: 2973-2978.

46. Ran FA, Hsu PD, Wright J, Agarwala V, Scott DA, Zhang F. Genome engineering using the CRISPR-Cas9 system. Nat Protoc 2013; 8: 2281-2308.

47. Mohr A, Lyons M, Deedigan L, Harte T, Shaw G, Howard L et al. Mesenchymal stem cells expressing TRAIL lead to tumour growth inhibition in an experimental lung cancer model. $J$ Cell Mol Med 2008; 12: 2628-2643.

48. Zwacka RM, Stark L, Dunlop MG. NF-kappaB kinetics predetermine TNF-alpha sensitivity of colorectal cancer cells. J Gene Med 2000; 2: 334-343.

49. Nicoletti I, Migliorati G, Pagliacci MC, Grignani F, Riccardi C. A rapid and simple method for measuring thymocyte apoptosis by propidium iodide staining and flow cytometry. J Immunol Methods 1991; 139: 271-279.

50. Stahnke K, Mohr A, Liu J, Meyer LH, Karawajew L, Debatin KM. Identification of deficient mitochondrial signaling in apoptosis resistant leukemia cells by flow cytometric analysis of intracellular cytochrome c, caspase-3 and apoptosis. Apoptosis 2004; 9: 457-465.

51. Feig C, Tchikov V, Schutze S, Peter ME. Palmitoylation of CD95 facilitates formation of SDSstable receptor aggregates that initiate apoptosis signaling. EMBO J 2007; 26: 221-231.

52. Mohr A, Zwacka RM. In situ trapping of initiator caspases reveals intermediate surprises. Cell Biol Int 2007; 31: 526-530.

\section{Supplementary Information accompanies this paper on Cell Death and Differentiation website (http://www.nature.com/cdd)}

